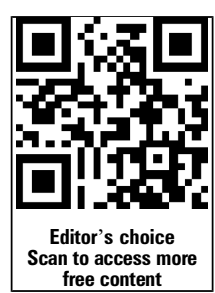

- Additional material is published online only. To view please visit the journal online (http://dx.doi.org/10.1136/ bjsports-2014-094036).

'Department of Physiotherapy, Meander Medical Centre, Amersfoort, The Netherlands ${ }^{2}$ Department of Clinical Epidemiology and Biostatistics, Academic Medical Center, University of Amsterdam, Amersfoort, The Netherlands ${ }^{3}$ Department of Sport Medical Care, FC Utrecht, Utrecht, The Netherlands ${ }^{4}$ Department of Sports Medicine, Bergman Clinics, Naarden, The Netherlands

${ }^{5}$ The Sportsphysician Group, Saint Lucas Hospital, Amsterdam, The Netherlands

Correspondence to Dr Maarten H Moen, Department of Sports Medicine, Bergman Clinics, Naarden $1411 \mathrm{GE}$

The Netherlands; m.moen@bergmanclinics.nl

Accepted 28 October 2014 Published Online First 21 November 2014

\title{
Efficacy of platelet-rich plasma injections in osteoarthritis of the knee: a systematic review and meta-analysis
}

\author{
Augustinus B M Laudy, ${ }^{1,2}$ Eric W P Bakker, ${ }^{2}$ Mark Rekers, ${ }^{3}$ Maarten H Moen ${ }^{4,5}$
}

ABSTRACT

Background The effectiveness of platelet-rich plasma

(PRP) injections for osteoarthritis (OA) is still

controversial. We investigated the effect of PRP injections

in patients with knee OA based on decreasing pain, improving function, global assessment and changes regarding joint imaging.

Methods We performed a comprehensive, systematic literature search in computerised databases (MEDLINE, EMBASE, CINAHL, CENTRAL, Web of Science and PEDro) until June 2014 for randomised or nonrandomised controlled trials. These were graded for risk of bias and a level of evidence was provided. If possible, meta-analysis was performed.

Results Ten trials were included. In these, intraarticular PRP injections were more effective for pain reduction (mean difference (MD) $-2.45 ; 95 \% \mathrm{Cl}-2.92$ to $-1.98 ; p$ value $<0.00001$ and $\mathrm{MD}-2.07 ; 95 \% \mathrm{Cl}$ -2.59 to -1.55 ; $p$ value $<0.00001$, single and double PRP injections, respectively) compared with placebo at 6 months postinjection. Intra-articular PRP injections were compared with hyaluronic acid and showed a statistically significant difference in favour of PRP on pain reduction based on the visual analogue scale and numeric rating scale (standardised mean difference $-0.92 ; 95 \% \mathrm{Cl}-1.20$ to -0.63 ; $p$ value $<0.00001$ ) at 6 months postinjection. Almost all trials revealed a high risk of bias.

Conclusions On the basis of the current evidence, PRP injections reduced pain more effectively than did placebo injections in $\mathrm{OA}$ of the knee (level of evidence: limited due to a high risk of bias). This significant effect on pain was also seen when PRP injections were compared with hyaluronic acid injections (level of evidence: moderate due to a generally high risk of bias). Additionally, function improved significantly more when PRP injections were compared with controls (limited to moderate evidence). More large randomised studies of good quality and low risk of bias are needed to test whether PRP injections should be a routine part of management of patients with $\mathrm{OA}$ of the knee.

\section{INTRODUCTION}

Osteoarthritis (OA) of the knee is a progressive disease involving the intra-articular (IA) tibiafemoral and patella-femoral cartilage and all other surrounding IA and periarticular structures. ${ }^{1}$ It is one of the most frequent causes of pain, loss of function and walking-related disability among older adults ( $>65$ years) in the USA. ${ }^{2-5}$

In older patients, who are refractory to conservative management, knee replacement surgery is the primary intended treatment for severe knee OA to relieve pain and improve function. Owing to the limited lifespan of joint replacements with implant wear and the associated risk for joint revision, conservative treatment modalities are the central focus in the younger and middle-aged population with cartilage damage and OA of the knee. ${ }^{6}$

The American College of Rheumatology (ACR) guidelines for the treatment of $\mathrm{OA}$ of the knee include non-pharmacological methods and pharmacological therapies. ${ }^{7}$ These modalities are effective but not without limitations. Non-pharmacological approaches such as exercise and lifestyle modification are often associated with poor compliance. ${ }^{8}$ Pharmacological therapies including analgesics, non-steroid and steroid anti-inflammatory drugs and corticosteroid injections provide only temporary benefit and often have side effects. ${ }^{9-11}$

There is an increasing clinical interest in autologous growth factor treatment such as the use of platelet-rich plasma (PRP) injections in $\mathrm{OA}$ of the knee. $^{12}{ }^{13}$ PRP is an autologous blood product with an elevated platelet concentration. ${ }^{14}$ Platelet-derived growth factors, stored in the $\alpha$ granulate of these increased concentration of platelets, regulate some biological processes in tissue repair. $^{15-18}$

The preparation of platelets from autologous blood is a simple procedure by using laboratory centrifuge or cell separators. The application of this growth factor treatment is safe and minimally invasive. ${ }^{14}$

Several case series have shown favourable results of IA PRP injections in patients with cartilage damage and OA of the knee. ${ }^{19-27}$ However, a number of controlled studies have demonstrated positive and negative outcomes. Due to these mixed results, we performed a systematic search of the literature to assess the effectiveness and safety over long and short time of PRP injections in patients with OA of the knee.

\section{METHODS}

Types of studies: Randomised controlled or nonrandomised controlled clinical trials in full text were potentially eligible for inclusion.

Types of participants: We considered patients (>18 years) diagnosed with monolateral or bilateral OA of the knee based on the criteria described by the ACR, Altman et al's ${ }^{28}$ classification criteria and clinical and radiological information.

Types of interventions: Studies of interest were all IA injections (preparations) with PRP or similar products (ie, autologous blood, platelet-leucocyte 
gel, platelet concentrate, platelet gel or PRGF-Endoret (Plasma Rich in Growth Factors-Endoret)) compared with control treatments including placebo, exercise treatment, joint lavage, IA hyaluronic acid (HA), IA corticosteroid, other IA PRP or doses of other IA PRP.

Types of outcomes: Studies reporting one of the OMERACT III core sets of outcome measures were eligible for inclusion: (1) pain; (2) physical function; (3) patient global assessment and (4) joint imaging. ${ }^{29}$

In addition, information about other outcome measures were extracted and analysed.

For assessment of adverse events, the following variables of interest were included: (1) short time local and systemic reactions, (2) infections and (3) withdrawals due to adverse events.

Search methods for identification of studies: We performed a comprehensive, systematic literature search in the electronic databases of MEDLINE, EMBASE, CINAHL, Web of Science and the Cochrane library without language or time restrictions until June 2014. Our search strategy (see addendum) was developed with help with a clinical librarian. For additional relevant studies, we examined the reference list of all included publications, consulted experts on this topic and used the 'related articles' feature in the used databases.

We searched the national (http://www.trialregister.nl) and international trial registries (http://www.controlled-trials.com); ClinicalTrials.gov and http://apps.who.int/trialsearch/ to identify ongoing studies. When an ongoing study was found, attempts were made to contact its primary investigator to collect further information.

Conference abstracts were searched to identify relevant unpublished studies in: OpenSigle (http://opensigle.inist.fr/); British Library Inside (http://www.bl.uk/inside); Web of Science and BIOSIS Previews (http://www.ovid.com). Also, we hand searched presentations and abstracts from annual meetings of the American Academy of Orthopaedic Surgeons (AAOS), the American Academy of Physical Medicine and Rehabilitation (AAPM\&R), the ACR and the Osteoarthritis Research Society International (OARSI). The search was performed independently by two reviewers (ABML, MR).

Study selection: After removing duplicates, all titles and abstracts were screened independently for potentially eligible studies by two reviewers (ABML, MHM). Reports of studies that were considered potentially relevant by at least one reviewer were retrieved in full text. The eligibility of the retrieved full-text articles for final inclusion was assessed independently by two reviewers (ABML, MHM). Disagreement was resolved through discussion and if no consensus was reached, a third reviewer (EWPB or MR) made the final decision.

Data extraction: Two reviewers (ABML, MHM) independently extracted the data of all the included studies using a standardised data extraction form to ensure uniform data collection.

The following data were extracted from all eligible studies:

- General study information: title, authors and publication year;

- Study characteristics: study design, study setting, inclusion/ exclusion criteria;

- Details of the interventions: dose, frequency of administration and duration of treatment;

- Primary and secondary outcome measures including the results in the intervention and the comparison groups from baseline to follow-up with the effect sizes and $\mathrm{p}$ values;

- Information regarding variables in the production of PRP used in the study protocols, such as the presence of white cells count, activation status, platelet concentration and the use of anticoagulants;
- Adverse events.

Differences in results of data extracted were resolved in an agreement meeting by the two reviewers. If questions remained after reading and extracting an article, the original authors of the study were contacted.

Quality assessment: Two independent reviewers (ABML, MHM) assessed the quality of the included randomised and non-randomised studies using the Cochrane Collaboration risk of bias tool. ${ }^{30}$ This tool contains the following domains: sequence generation-allocation sequence concealment-blinding of participants, personnel and outcome assessors-incomplete outcome data-selective outcome reporting and other potential threats to validity. We assessed risk of bias in each domain of all included studies using a risk of bias table. We determined an item as 'low risk' of bias (+), 'high risk' of bias $(-)$ or 'unclear risk' of bias (?), respectively. ${ }^{30}$ Trials were considered as low risk of bias when on every single item of bias a ' + ' was scored; if studies scored '-' or '?' on one or two items of bias, a moderate bias was considered. Studies with more than two '-' or '?' were considered as high risk of bias. Differences were settled by discussion and in case of disagreement, the third reviewer (EWPB) made the final decision.

To assess the level of evidence for an intervention, best-evidence synthesis was used. ${ }^{31}$ The results of the risk-of-bias assessments of the individual studies were used to classify the level of evidence. ${ }^{32}$ This qualitative analysis was performed with five levels of evidence based on the risk of bias and results of the included studies:

1. Strong evidence: provided by two or more studies with a low risk of bias and by generally consistent findings in all studies ( $\geq 75 \%$ of the studies reported consistent findings).

2. Moderate evidence: provided by one study with a low risk of bias and/or two or more studies with a high risk of bias, and by generally consistent findings in all studies $(\geq 75 \%$ of the studies reported consistent findings).

3. Limited evidence: provided by only one study with a high risk of bias.

4. Conflicting evidence: inconsistent findings in multiple studies ( $\geq 75 \%$ of the studies reported consistent findings).

5. No evidence: when no studies could be found.

Data syntheses: The results of the studies were analysed using RevMan 5.2. If the data were sufficiently homogeneous (clinical and statistical), we summarised these in a meta-analysis. Continuous outcomes were calculated and expressed as the mean difference (MD) or as the standardised MD (SMD) depending on the similarity of the used scales. Dichotomous data were expressed as the relative risk (RR).To measure heterogeneity between studies, we used the $\chi^{2}$ ( $\mathrm{p}$ value less than 0.10 indicates heterogeneity) and $\mathrm{I}^{2}$ statistic (a value of less than $40 \%$ represents low heterogeneity and a value of $75 \%$ or more indicates high heterogeneity). The outcomes were pooled using random-effects models. Fixed-effects models were used when less than five studies could be included.

In case of heterogeneity, we planned a subgroup and metaregression analysis to explore possible differences in PRP preparation, dose of PRP, age of study population, duration of follow-up or methodological features and the results are presented in a descriptive summary of findings table.

For pain, we identified pain on a visual analogue scale (VAS) or the numeric rating scale (NRS). If this was not available, we used the Western Ontario and McMaster Universities Osteoarthritis Index (WOMAC) pain subscale (percentage of people with a $50 \%$ decrease, VAS or Likert). For function, we used the WOMAC physical function subscale $(50 \%$ decrease, 
VAS or Likert) as the primary measure of function followed by the WOMAC total score and the Lequesne index.

\section{RESULTS}

Results of the search

The search of electronic databases and other sources in June 2014 resulted in 371 articles (see figure 1). After combining the results, removing duplicates and selections based on the title and abstract, 14 full-text articles remained. Four studies were excluded after reviewing the full text. Two were excluded because they did not examine the intervention of interest ${ }^{33} 34$ and one was a point/counterpoint discussion. ${ }^{35}$ The search in the trial registers resulted in three trials, two ongoing trials and one trial which was characterised as completed. We were unable to obtain additional information regarding this trial for inclusion in this systematic review. In total, 10 studies with 1110 patients met the predefined inclusion criteria. ${ }^{36-45}$ The trials were published between 2011 and 2013.

\section{Description of studies}

See online supplementary materials: Characteristics of included studies; Characteristics of excluded studies; Characteristics of ongoing studies.

\section{Design}

Six studies were reported to be randomised controlled trials (RCT). One of these compared PRP with placebo, ${ }^{37}$ whereas the other five studies compared PRP with HA. ${ }^{36} 38-4043$

Four studies were non-randomised clinical trials. Three included comparisons of PRP with $\mathrm{HA}^{414245}$ and one study compared single versus double spinning in the preparation of the PRP. ${ }^{44}$

\section{Sample sizes}

The mean number of patients randomised was 102 and ranged from 30 to $176 .{ }^{40} 43$ The total follow-up of seven trials ${ }^{37} 39-4345$ was 6 months and that of three trials ${ }^{36} 3844$ had a duration of 12 months.

\section{Participants}

The average age in the randomised and non-randomised controlled trials was 59.5 years (range 52.8-66.4) and 53.4 years (range 52.1-55.7), respectively.

Both clinical criteria, as proposed by the recommendations of the ACR, and two different radiological grading systems were used to include patients with OA. The severity of OA was classified with the Ahlbäck classification by Patel $e t a l^{37}$ and Sánchez et $a l^{40}$ (mode of grade OA in both the PRP group and the control group was 1), whereas five authors ${ }^{36} 3941-43$ used the Kellgren and Lawrence $(\mathrm{K} \& \mathrm{~L})$ classification system (mode of grade OA in the PRP group and the control group was 2; figure 2A, B). Three studies were excluded in the pooling of OA severity. Filardo $e a^{23}$ and Kon $e t a l^{1645}$ grouped grading scales and Filardo et $a l^{38} 44$ reported mean values.

\section{Intervention}

In five of the 10 trials the single spin procedure for the preparation of the PRP was used ${ }^{36} 37$ 39-41 whereas three trials reported a double spin procedure. ${ }^{38} 4345$ One trial used both techniques and compared them (single spinning vs double spinning approach). ${ }^{44}$ Spaková $e t ~ a l^{42}$ used a three spinning technique.

Most trials used a dosage of three IA injections on a one, two or three weekly basis. ${ }^{36} 384042-45$ In the Patel et $a l^{37}$ and the Say $e \mathrm{al}^{41}$ trials, a dosage of one IA injection was used, whereas Cerza et $a l^{39}$ used a dosage of four injections at weekly intervals.

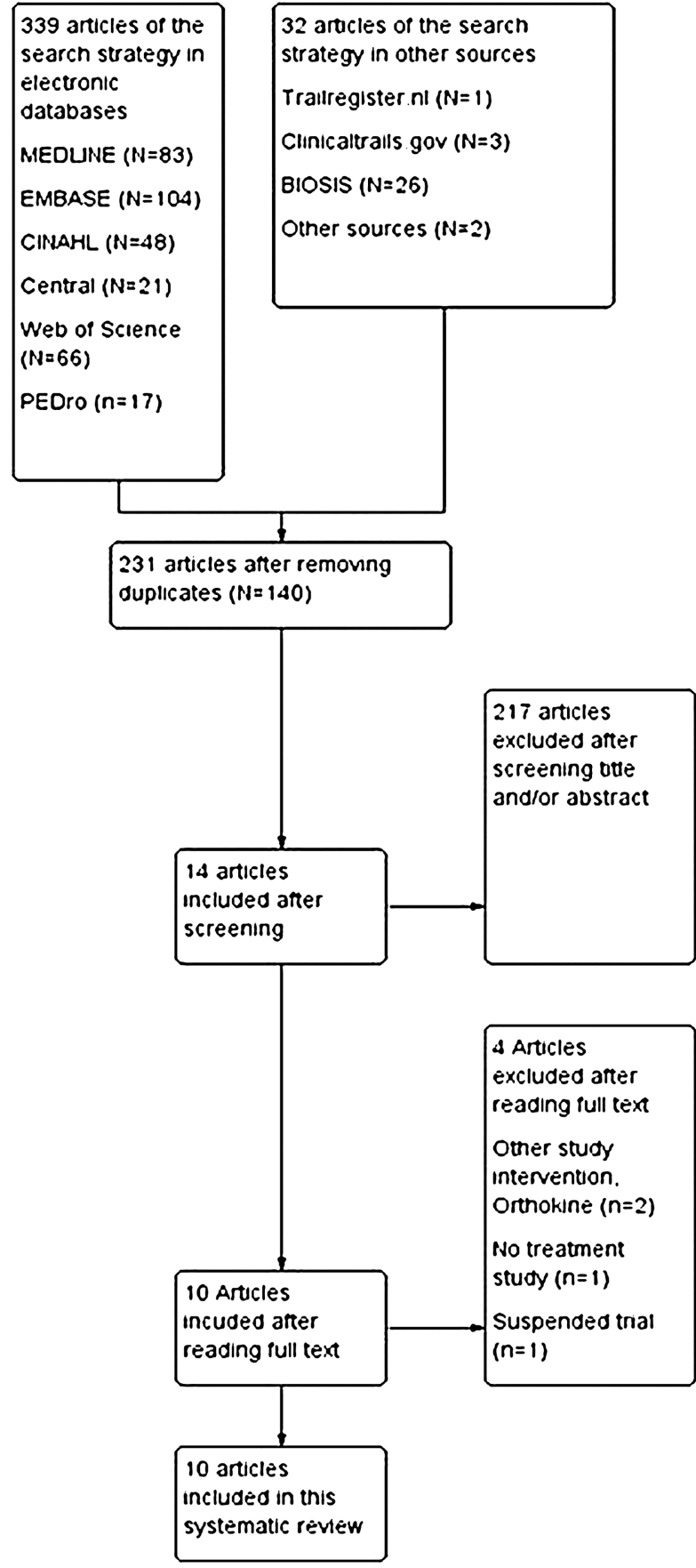

Figure 1 Study flow diagram.

In addition, the authors of the included studies were contacted by mail to obtain more detailed information of the used PRP. The results were categorised following the Mishra et $a l^{46}$ classification system (table 1).

\section{Outcomes}

All trials reported a minimal one of the OMERACT III core sets of outcome measures. Primary outcome measures to assess pain and function were the VAS or NRS for pain and the WOMAC physical function subscale, respectively. Secondary outcome measures for pain included the WOMAC pain subscale, and those for function were inclusive of the WOMAC total index and Lequesne index. 
Figure 2 Severity of osteoarthritis $(O A)$ on baseline classified by the Ahlbäck system.
A

\section{Severity of OA on baseline}

Patel 2013; Sánchez 2012

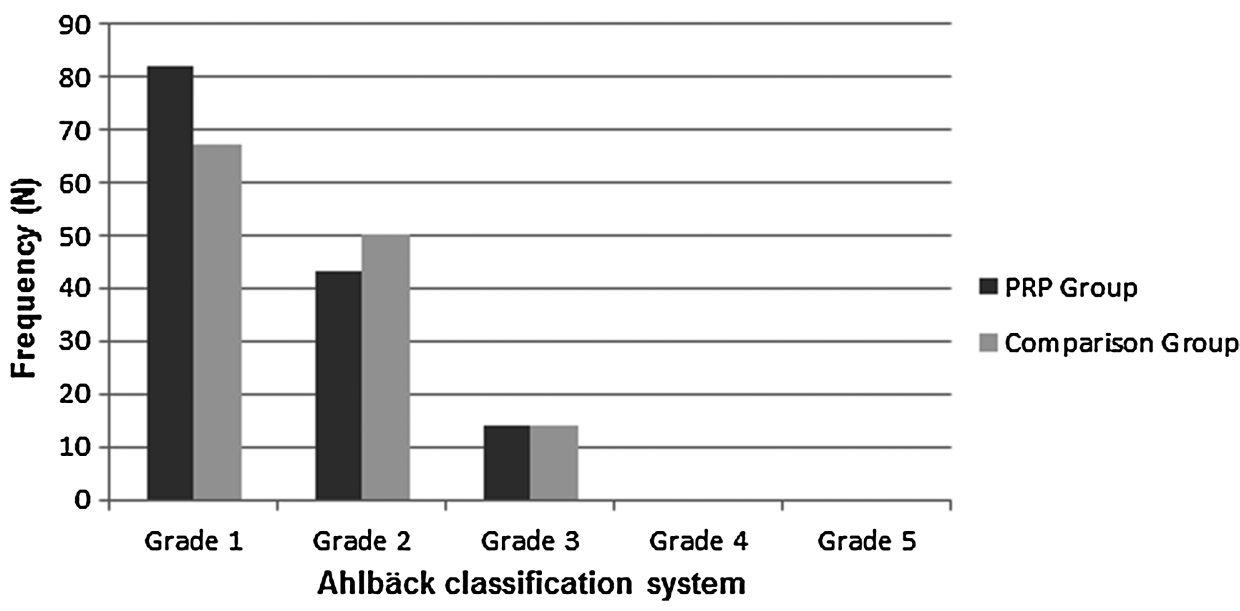

B

Severity of $O A$ on baseline

Cerza 2012; Li 2011; Say 2013; Spaková 2012; Vaquerizo 2013

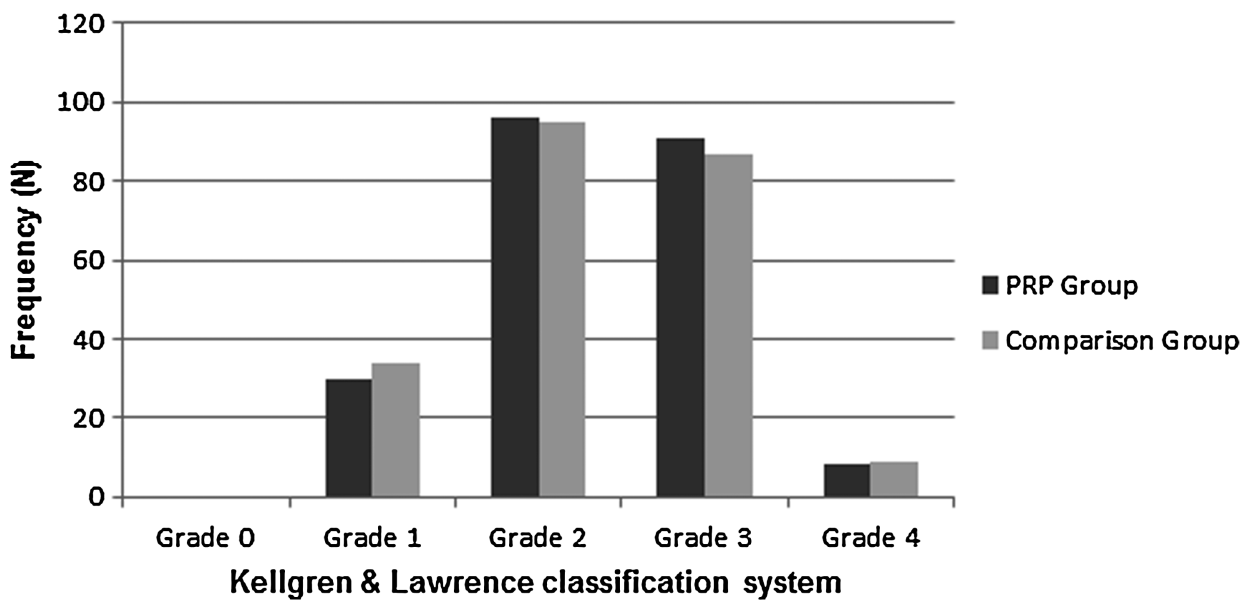

Table 1 Details of the used PRP compilation and Mishra classification of PRP

\begin{tabular}{|c|c|c|c|c|c|c|}
\hline References & $\begin{array}{l}\text { Injections (N)/interval } \\
\text { (weeks)/volume (mL) }\end{array}$ & Spinning approach & White cells count & Activation & Platelet concentration & $\begin{array}{l}\text { Type PRP (Mishra } \\
\text { classification) }\end{array}$ \\
\hline Vaquerizo et $a l^{36 *}$ & $3 / 2 / 8$ & Single spinning & - & + & $<5 \times$ baseline & $4 B$ \\
\hline Patel et $a l^{37 *}$ & $1(2) /-(3) / 8$ & Single spinning & - & + & $<5 \times$ baseline & $4 B$ \\
\hline Filardo et $a l^{3844 *}$ & $3 / 1 / 5$ & Double spinning & + & + & $5 \times$ baseline & $2 \mathrm{~A}$ \\
\hline Cerza et $a \beta^{39 *}$ & $4 / 1 / 5.5$ & Single spinning & - & - & $>5 \times$ baseline & $3 \mathrm{~A}$ \\
\hline Sánchez et $\left.a\right|^{40 *}$ & $3 / 1 / 8$ & Single spinning & - & + & $<5 \times$ baseline & $4 \mathrm{~B}$ \\
\hline Say et $a l^{41}$ & $1 /-/ 2.5$ & Single spinning & - & + & $<5 \times$ baseline & $4 \mathrm{~B}$ \\
\hline Spaková et al ${ }^{42}$ & $3 / 1 / 3$ & 3 spinnings & + & - & $<5 \times$ baseline & $1 \mathrm{~B}$ \\
\hline Li et $a l^{43}$ & $3 / 3 / 3.5$ & NA & NA & + & NA & NA \\
\hline Filardo et $a l^{23}$ & $3(3) / 3(3) / 5(5)$ & Single vs double spinning & $-(+)$ & $+(+)$ & $<5 \times$ baseline & $4 B(2 B)$ \\
\hline Kon et $a l^{1645}$ & $3 / 2 / 5$ & Double spinning & + & + & $>5 \times$ baseline & $2 \mathrm{~A}$ \\
\hline
\end{tabular}

Type 1 PRP: increased white cells count and no activation; type 2 PRP: increased white cells count and activated; type 3 PRP: minimal/no white cells count and no activation; type 4 PRP: minimal/no white cells count and activated.

A: contains an increased platelet concentration at or above five times baseline (extracted venous blood).

B: contains an increased platelet concentration less than five times baseline (extracted venous blood).

* Included randomised controlled trials.

Values in brackets in the Patel's study: group B (2 platelet-rich injections).

Values in brackets in the Filardo's study: comparison group (double-spinning approach).

NA, not applicable; PRP, platelet-rich plasma. 
Table 2 Overview of outcome measures per study

\begin{tabular}{|c|c|c|c|c|c|c|c|c|}
\hline \multirow[b]{3}{*}{$\begin{array}{l}\text { Study } \\
\text { type }\end{array}$} & \multirow[b]{3}{*}{$\begin{array}{l}\text { Intervention/ } \\
\text { comparison }\end{array}$} & \multicolumn{7}{|c|}{ OMERACT III set of outcome measures } \\
\hline & & \multicolumn{2}{|l|}{ Pain } & \multicolumn{3}{|l|}{ Function } & \multirow{2}{*}{$\begin{array}{l}\begin{array}{l}\text { Global } \\
\text { assessment }\end{array} \\
\text { Patient } \\
\text { satisfaction }\end{array}$} & \multirow{2}{*}{$\begin{array}{l}\text { Joint imaging } \\
\text { Scoring radiographs or demonstrably } \\
\text { superior imaging techniques }\end{array}$} \\
\hline & & $\begin{array}{l}\text { VASI } \\
\text { NRS }\end{array}$ & $\begin{array}{l}\text { WOMAC } \\
\text { pain }\end{array}$ & $\begin{array}{l}\text { WOMAC } \\
\text { physical } \\
\text { function }\end{array}$ & $\begin{array}{l}\text { WOMAC } \\
\text { total }\end{array}$ & $\begin{array}{l}\text { Lequesne } \\
\text { index }\end{array}$ & & \\
\hline RCTs & $\begin{array}{l}\text { PRP-placebo } \\
\text { PRP-HA }\end{array}$ & $\sqrt{ } 1$ & $\begin{array}{l}\sqrt{ } 1^{*} \\
\sqrt{ } 2,3\end{array}$ & $\begin{array}{l}\sqrt{ } 1^{*} \\
\sqrt{ } 2,3\end{array}$ & $\begin{array}{l}\sqrt{ } 1^{*} \\
\sqrt{ } 2,3,4,5\end{array}$ & - & $\begin{array}{l}\sqrt{1} \\
\sqrt{6^{*}}\end{array}$ & $\begin{array}{l}- \\
-\end{array}$ \\
\hline CCTs & PRP-HA & $\sqrt{7}, 8$ & - & - & $\sqrt{8}$ & - & $\sqrt{7},{ }^{* 9}$ & - \\
\hline CCTs & PRP-PRGF & - & - & - & - & - & $\sqrt{10}$ & - \\
\hline
\end{tabular}

Postinjection follow-up moments varied between studies. All included studies, however, reported pain, function or global assessment at 6 months postinjection.

An overall summary regarding the outcome measures used in the included studies is provided in table 2 .

\section{Quality assessment}

All randomised and non-randomised trials, except Sánchez's et $a l^{40}$ trial which achieved a moderate risk of bias, obtained a high risk of bias.

A summary of the risk of bias of the included studies can be found in figure 3A, B. A more detailed justification for assigning low risk, high risk or unclear risk to each domain of bias is described and provided in the characteristics of the included studies table.

\section{Effect of intervention}

The included randomised and non-randomised trials assessed the effect of IA PRP injections compared with placebo and HA, respectively. For an overview of their effects, see table 3 and figures 4-23. One non-randomised trial assessed the effect of PRP compared with another IA PRP.

\section{Data analysis}

Fixed-effect models were used to estimate the effect of PRP versus HA. No statistical heterogeneity was present on the outcome pain identified on a VAS or the NRS (forest plot comparison 3, outcome 3.1). When pooled the outcome measures WOMAC pain subscale (percentage of people with a $50 \%$ decrease, VAS or Likert), WOMAC physical function, WOMAC total or Lequesne index, considerable heterogeneity was present (forest plot comparison 2 outcomes: 2.2-2.3-2.6-2.7-2.10). No meta-regression or subgroup analyses to test heterogeneity could be performed because four or less studies assessed the effect of PRP with a similar outcome and follow-up.

No statistical heterogeneity was present when pooling data on the outcome adverse events (forest plot comparison 2, outcome 2.16).

\section{PRP versus placebo}

Patel et $a l^{37}$ detected a statistically significant difference on a $0-10 \mathrm{~cm}$ VAS in favour of the single PRP injection and the two PRP injections compared with saline at 6 months postinjection (MD $-2.45 ; 95 \%$ CI -2.92 to -1.98 ; $\mathrm{p}$ value $<0.00001$, MD -2.07 ; $95 \%$ CI -2.59 to -1.55 ; $\mathrm{p}$ value $<0.00001$ ).
Patel et $a l^{37}$ reported that for both pain and physical function, as assessed by WOMAC, ${ }^{47}$ the improvement at 6 weeks, 3 and 6 months, was greater in the single spin and double spin procedure compared to placebo $(p<0.001)$. Since no measure of dispersion (ie, SD, SE) was reported, these outcomes were not included in the RevMan analysis.

The same trial reported the percentage of patients who were satisfied with the procedure at 6 months postinjection. A statistically significant difference was detected in favour of the single PRP injection and the two PRP injections compared with saline. RR was 8.40 (95\% CI 2.19 to 32.24 ; p value 0.002 ), RR was 7.82 (95\% CI 2.02 to 30.20 ; p value 0.003 ).

Finally, no statistically significant difference was detected in the total number of patients with short time local and systemic reactions during and after the injections between the one PRP injection group and the saline group. RR was 11.14 (95\% CI 0.66 to 187.75 ; $\mathrm{p}$ value 0.09 ). A statistically significant difference was detected between the two PRP injections group and the saline group; RR was 21.23 (95\% CI 1.32 to 341.04 ; $p$ value 0.03). For details, please see the effect estimates (see online supplementary materials).

Level of evidence (pain and function)

Limited evidence (one study with a high risk of bias) is available that PRP injections reduce pain significantly more than do placebo injections. Limited evidence (one study with a high risk of bias) is available that function (WOMAC) is improved significantly better after PRP injections compared with placebo.

\section{PRP versus HA}

For details, please see table 3 and figures 10-22.

\section{Level of evidence (pain)}

Moderate evidence ( $\geq 75 \%$ of the studies had consistent findings but displayed a high risk of bias) is available that PRP injections reduce pain significantly more than do HA injections.

Regarding physical function, Vaquerizo et $\mathrm{al}^{36}$ reported a statistically significant difference between PRP and HA in the number of patients reporting a $50 \%$ decrease in the WOMAC physical function score at both 6 months and 48 weeks postinjection (RR 3.80; 95\% CI 1.54 to 9.35 ; p value 0.004 and RR 27.20 ; $95 \%$ CI 1.68 to 441.24 ; p value 0.02 , respectively). This trial also detected a statistically significant difference in favour of PRP for the WOMAC physical function (0-68 Likert) at 6 months and 48 weeks postinjection (MD $-16.50 ; 95 \% \mathrm{CI}$ -22.20 to $-10.80 ; \mathrm{p}$ value $<0.00001, \mathrm{MD}-17.00 ; 95 \% \mathrm{CI}$ 
Figure 3 (A) Risk of bias graph: review authors' judgements about each risk of bias item presented as percentages across all included studies. (B) Risk of bias graph: review authors' judgements about each risk of bias item for each included study.
$A_{\text {Random sequence gener ation (selection bias) }}$

Allocation concealment(selection bias)

Blinding of participants (performance bias)

Blinding of personnel (performance bias)

Blinding of outcome assessment(detection bias)

Incomplete outcome data (attition bias)

Selective reporting (reporting bias)

Other bias
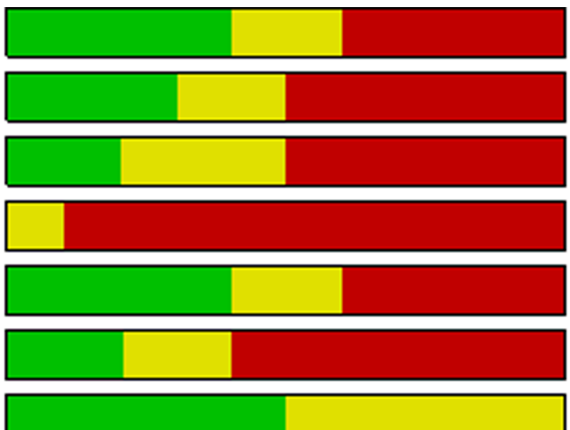

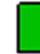

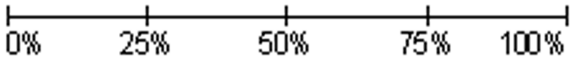

Low risk of bias

Unclear risk of bias

High risk of bias

B

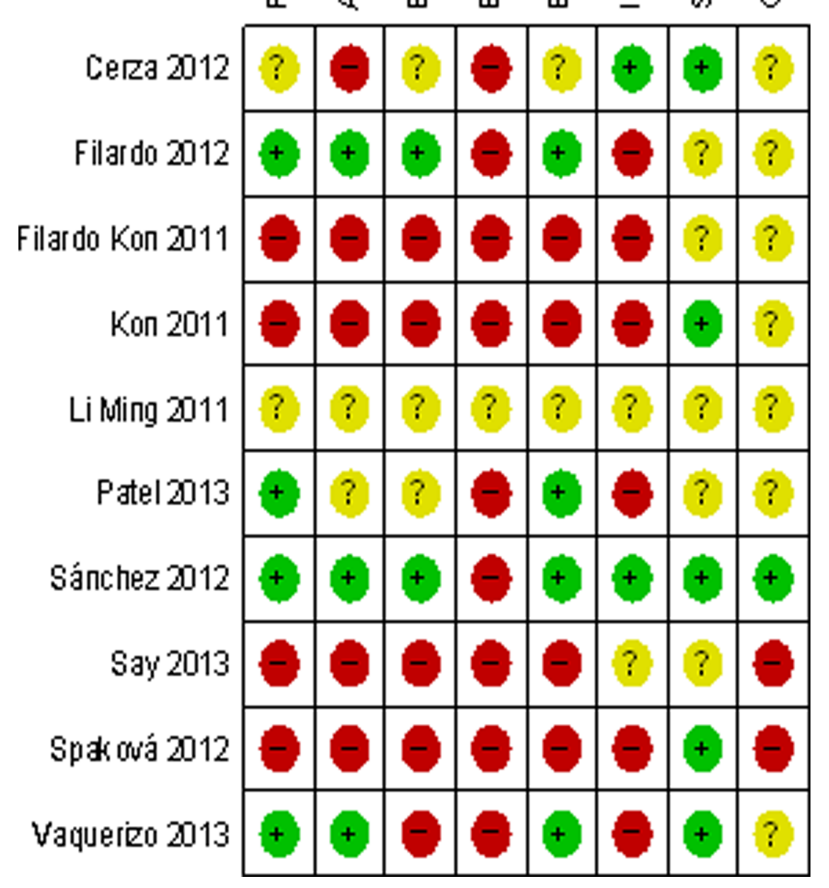


Table 3 Overview of intervention effect per study in time

\begin{tabular}{|c|c|c|c|c|c|}
\hline Study & Outcome & Subgroup & $\begin{array}{l}3 \text { months } \\
\text { postinjection }\end{array}$ & $\begin{array}{l}6 \text { months } \\
\text { postinjection }\end{array}$ & $\begin{array}{l}12 \text { months } \\
\text { postinjection }\end{array}$ \\
\hline \multirow[t]{5}{*}{$\begin{array}{l}\text { Vaquerizo } \\
\text { et } a l^{36}\end{array}$} & Pain & $\begin{array}{l}\text { Percentage of patients having a } 50 \% \text { decrease in the WOMAC pain } \\
\text { subscale }\end{array}$ & & + & + \\
\hline & Function & $\begin{array}{l}\text { Percentage of patients having a } 50 \% \text { decrease in the WOMAC } \\
\text { physical function subscale }\end{array}$ & & + & + \\
\hline & & $\begin{array}{l}\text { Percentage of patients having a } 50 \% \text { decrease in the Lequesne } \\
\text { index }\end{array}$ & & + & + \\
\hline & & WOMAC total score & & + & + \\
\hline & & Lequesne index & & + & + \\
\hline Cerza et $a l^{39}$ & Function & WOMAC total score & + & + & \\
\hline \multirow[t]{5}{*}{ Sánchez et $\left.a\right|^{40}$} & Pain & $\begin{array}{l}\text { Percentage of patients having a } 50 \% \text { decrease in the WOMAC pain } \\
\text { subscale }\end{array}$ & & + & \\
\hline & & WOMAC pain subscale & & - & \\
\hline & Function & WOMAC physical function subscale & & - & \\
\hline & & WOMAC total score & & - & \\
\hline & & Lequesne index & & - & \\
\hline \multirow[t]{2}{*}{ Li et $a l^{43}$} & Function & WOMAC total score & - & + & \\
\hline & & Lequesne index & - & + & \\
\hline \multirow{2}{*}{$\begin{array}{l}\text { Spaková } \\
\text { et } a l^{42}\end{array}$} & Pain & NRS & + & + & \\
\hline & Function & WOMAC total score & + & + & \\
\hline Say et al ${ }^{41}$ & Pain & VAS & + & + & \\
\hline
\end{tabular}

-22.35 to $-11.65 ; \mathrm{p}$ value $<0.00001$, respectively). No statistically significant differences between PRP and HA were detected on the normalised WOMAC physical subscale (0-100) at 6 months postinjection in Sánchez et al's ${ }^{40}$ trial (MD -1.10; $95 \% \mathrm{CI}-6.00$ to 3.80 ; $\mathrm{p}$ value 0.66 ). When pooling these data, heterogeneity was present (SMD $-0.41 ; 95 \% \mathrm{CI}-0.65$ to -0.17 ; $p$ value $\left.0.001, \chi^{2} 16.40 \mathrm{df}=1, \mathrm{I}^{2}=94 \%\right)$.

Function, assessed with the WOMAC total score (0-96 Likert), showed a statistically significant difference in favour of PRP compared with $\mathrm{HA}$ at 3 months (pooled SMD -0.93 ; 95\% CI -1.27

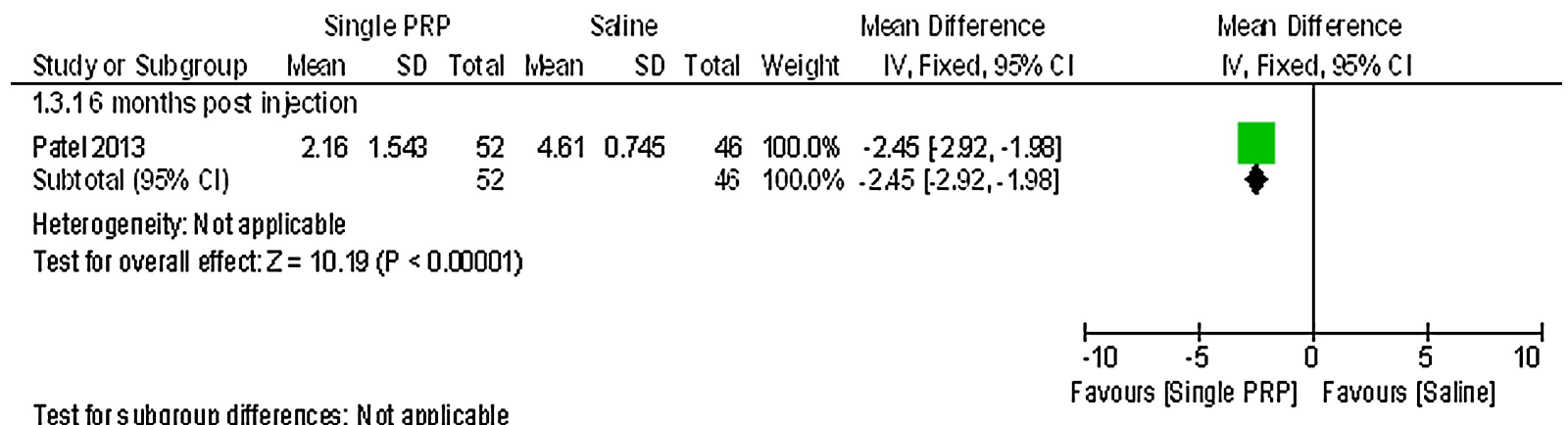

Figure 4 Forest plot of comparison: 1 platelet-rich plasma (PRP) versus placebo, outcome: 1.3; pain: visual analogue scale (single PRP vs saline).

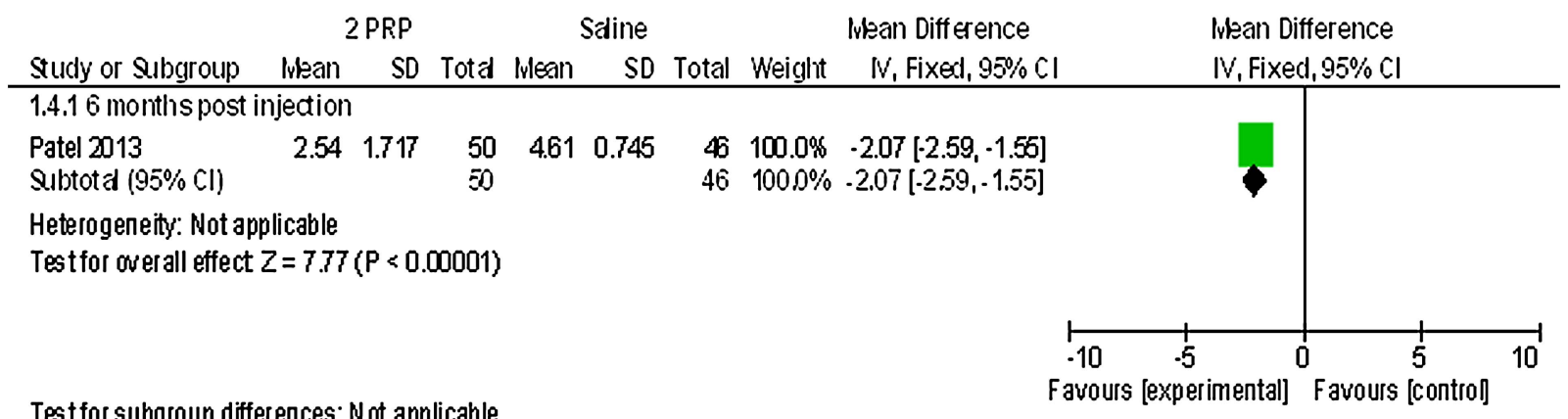

Figure 5 Forest plot of comparison: 1 platelet-rich plasma (PRP) versus placebo, outcome: 1.4; pain: visual analogue scale (2 PRP vs saline). 
Single PRP

Saline

Risk Ratio

In-H, Fixed, 95\% Cl

Studly or Subgroup Events

Patel 2013

Subtotal $(95 \% \mathrm{Cl})$

19

Total events 19

Heterogeneity. Not applicable

Test for overall effed: $Z=3.10(P=0.002)$

Test for subaroup differences: Not applicable
Risk Ratio

IHLH, Fixed, $95 \% \mathrm{Cl}$

Figure 6 Forest plot of comparison: 1 platelet-rich plasma (PRP) versus placebo, outcome: 1.9; global assessment: patient satisfaction, number of patients who were satisfied (single PRP vs saline).

2 PRP Saline Risk Ratio $\quad$ Risk Ratio

Events Total Events Total Weight IiH, Fixech, 95\% Cl IMIH, Fixed, 95\% Cl

Study or Subgroup Events

$\begin{array}{lllllll}\text { Patel } 2013 & 17 & 25 & 2 & 23 & 100.0 \% & 7.82[2.02,30.20] \\ \text { Suldtotal }(95 \% \mathrm{Cl}) & & 25 & & 23 & \mathbf{1 0 0 . 0 \%} & 7.82[2.02,30.20] \\ \text { Total events } & 17 & & 2 & & & \end{array}$

Heterogeneity. Not applicable

Test for overall effed: $Z=2.98(P=0.003)$

Test for subqroup difference: Not applicable

Figure 7 Forest plot of comparison: 1 platelet-rich plasma (PRP) versus placebo, outcome: 1.10; global assessment: patient satisfaction, number of patients who were satisfied (2 PRP vs saline).

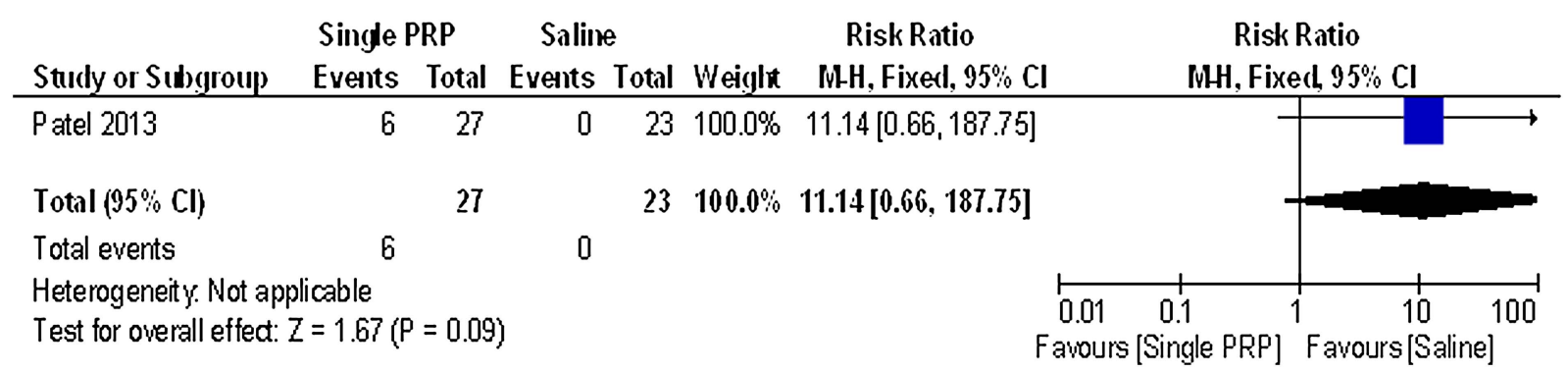

Figure 8 Forest plot of comparison: 1 platelet-rich plasma (PRP) versus placebo, outcome: 1.13; adverse effects: number of patients with local or systemic reactions related to treatment (single PRP vs saline).

\begin{tabular}{|c|c|c|c|c|c|c|c|c|}
\hline Study or Subgroup & $\begin{array}{r}2 \mathrm{PR} \\
\text { Events } \\
\end{array}$ & & $\begin{array}{r}\text { Salin } \\
\text { Events }\end{array}$ & Total & Weight & $\begin{array}{l}\text { Risk Ratio } \\
\text { [ul-H, Fixerl, } 95 \% \mathrm{Cl}\end{array}$ & $\begin{array}{r}\text { Risk } \\
\text { IM-H, Fixe }\end{array}$ & $\begin{array}{l}\text { Ratio } \\
\text { ecl, } 95 \% \mathrm{Cl}\end{array}$ \\
\hline P atel 2013 & 11 & 25 & 0 & 23 & $100.0 \%$ & $21.23[1.32,341.04]$ & & \\
\hline Total $(95 \% \mathrm{Cl})$ & & 25 & & 23 & $100.0 \%$ & $21.23[1.32,341.04]$ & & \\
\hline Total events & 11 & & 0 & & & & & \\
\hline \multicolumn{7}{|c|}{$\begin{array}{l}\text { Heterogeneity. Not applicable } \\
\text { Test for overall effed: } Z=2.16(P=0.03)\end{array}$} & $\begin{array}{ll}0.01 & 0.1 \\
\text { Favours [2PRP] }\end{array}$ & $\begin{array}{c}10 \\
\text { Favours [Saline] }\end{array}$ \\
\hline
\end{tabular}

Figure 9 Forest plot of comparison: 1 platelet-rich plasma (PRP)versus placebo, outcome: 1.14; adverse effects: number of patients with local or systemic reactions related to treatment (2 PRP vs saline). 
PRP

HA

Risk Ratio

Risk Ratio

Study or Subgroup Events Total Events Total Weiglt In-H, Fixed, $95 \% \mathrm{Cl}$

IVL-H, Fixed, $95 \% \mathrm{Cl}$

2.2.1 6 months post injection

Sánchez 2012

Vaquerizo 2013

34

Subtotal $(95 \% \mathrm{Cl})$

$26 \quad 48$

$21 \quad 87 \quad 80.9 \%$

$1.58[1.00,2.50]$

137

$5 \quad 48 \quad 19.1 \%$

$5.20[2.18,12.41]$

$2.27[1.53,3.38]$

Total events $\quad 60 \quad 26$

Heterogeneity. $\mathrm{Chi}^{2}=5.89, \mathrm{df}=1(\mathrm{P}=0.02) ; \mathrm{I}^{2}=83 \%$

Test for overall effect: $Z=4.05(P<0.0001)$

\subsubsection{2 months post injection}

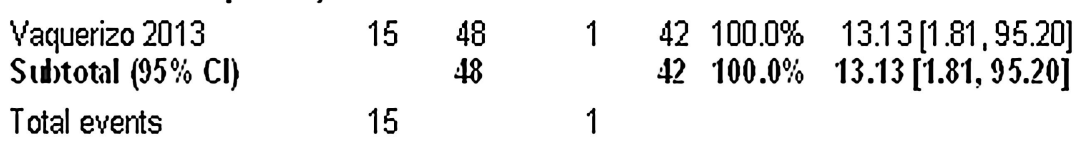

Heterogeneity. Not applicable

Test for overall effect: $Z=2.55(P=0.01)$

Test for subcroup differences $\mathrm{Chi}^{2}=2.89 . \mathrm{df}=1(\mathrm{P}=0.09) . \mathrm{I}^{2}=65.4 \%$

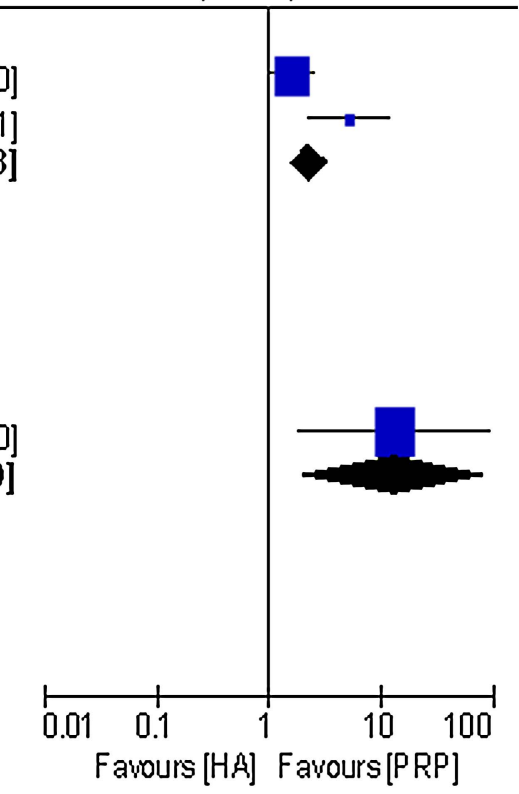

Figure 10 Forest plot of comparison: 2 platelet rich plasma (PRP) versus hyaluronic acid (HA), outcome: 2.2; pain: number of patients with $50 \%$ decrease on Western Ontario and McMaster Universities Osteoarthritis Index (WOMAC) pain subscale.

to $-0.59 ; \mathrm{p}$ value 0.00001$)^{39} 43$ and 6 months (pooled SMD $-0.81 ; 95 \%$ CI -1.02 to -0.61 ; p value $<0.00001) .{ }^{36} 394043$ However, considerable heterogeneity was present $\left(\chi^{2}=7.20 \mathrm{df}=1\right.$, $\mathrm{I}^{2}=86 \%$ and $\chi^{2}=51.09 \mathrm{df}=3, \mathrm{I}^{2}=94 \%$, respectively). At 48 weeks postinjection, the Vaquerizo et $a l^{36}$ trial also showed a statistically significant difference using the WOMAC total score (0-96 Likert; SMD -1.34 ; $95 \%$ CI -1.80 to -0.88 ; $\mathrm{p}$ value $<0.00001)$.

Considerable heterogeneity was also present in the Lequesne index (0-24) at 6 months postinjection (pooled MD -1.24; 95\% CI -1.90 to -0.58 ; $\mathrm{p}$ value $<0.00001, \chi^{2}=20.71 \mathrm{df}=1, \mathrm{I}^{2}=90 \%$ ) in the Vaquerizo et $a l^{36}$, Sánchez et $a l^{40}$ and Li et $a l^{43}$ trials.

Vaquerizo et al also detected a statistically significant difference in favour of PRP in the number of patients reporting a $50 \%$ decrease in the Lequesne index at 6 months (RR 7.00;
95\% CI 1.68 to 29.15 ; p value 0.008 ), but no statistically significant difference was found at 48 weeks postinjection (RR 7.88; 95\% CI 1.04 to 59.61 ; p value 0.05 ).

Regarding the non-randomised trials, Spaková et $a l^{42}$ assessed function with the WOMAC total score at 3 and 6 months postinjection. A statistically significant difference in favour of PRP was found at both postinjection follow-up periods (MD -11.82; $95 \% \mathrm{CI}-17.51$ to -6.13 ; $\mathrm{p}$ value $<0.00001$ and $\mathrm{MD}-12.05$; $95 \% \mathrm{CI}-17.55$ to -6.55 ; $\mathrm{p}$ value $<0.00001)$. For details, please see the effect estimates (see online supplementary materials).

Level of evidence (function)

Limited to moderate evidence is available that function (expressed as a 50\% decrease of the WOMAC physical function

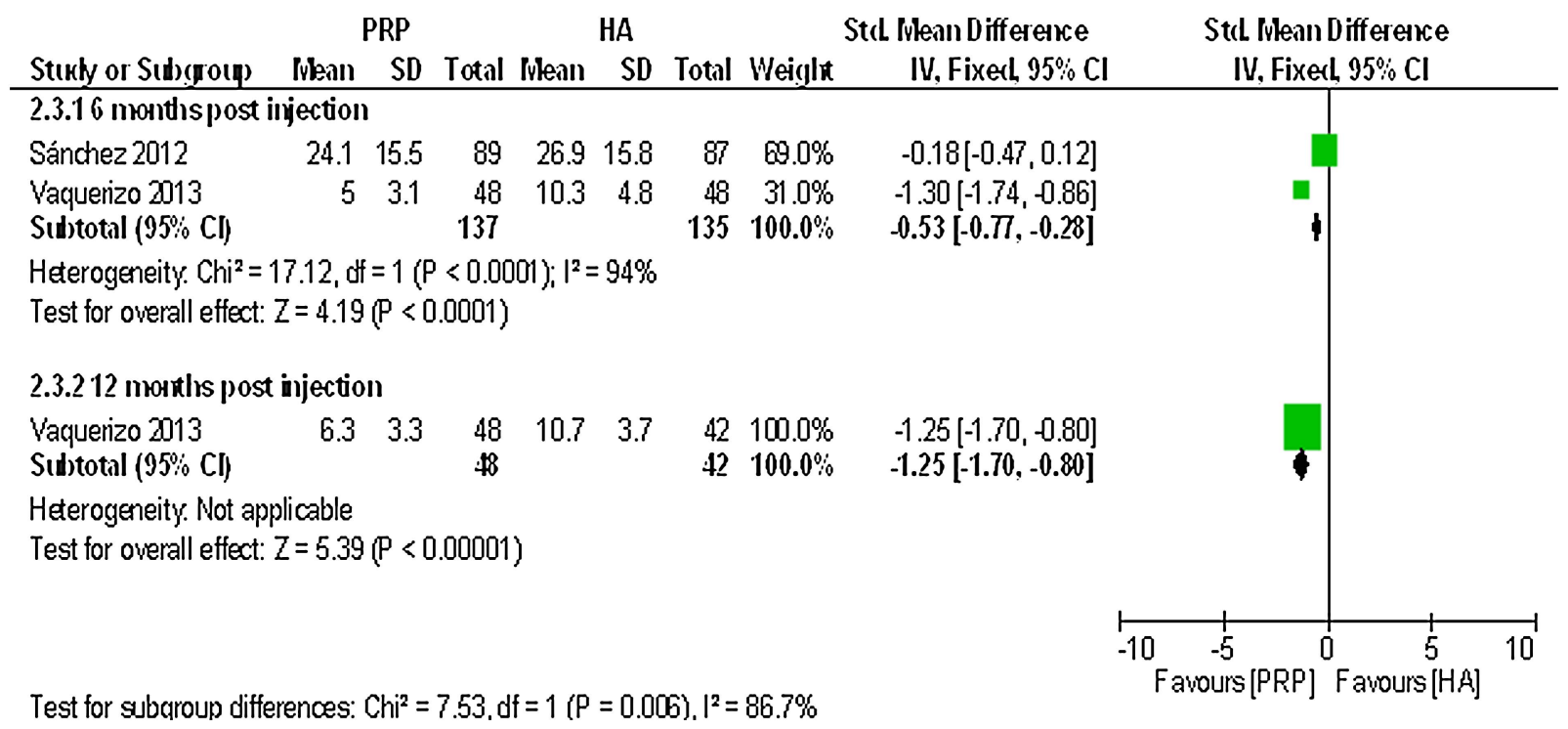

Figure 11 Forest plot of comparison: 2 platelet rich plasma (PRP) versus hyaluronic acid (HA), outcome: 2.3; pain: Western Ontario and McMaster Universities Osteoarthritis Index (WOMAC) pain subscale. 
PRP

HA

Risk Ratio

Risk Ratio

Study or Sudgroup Events Total Events Total Weight IILH, Fixed, $95 \% \mathrm{Cl}$

Inl-H, Fixech, $95 \% \mathrm{Cl}$

2.5.1 6 months post injection

Vaquerizo 2013

Sultotal $(95 \% \mathrm{Cl})$

19

$\begin{array}{llll}48 & 5 & 48 & 100.0 \% \\ 48 & & 48 & 100.0 \%\end{array}$

$3.80[1.54,9.35]$

$3.80[1.54,9.35]$

Total events

19

5

Heterogeneity. Not applicable

Test for overall effec: $Z=2.91(P=0.004)$

\subsubsection{2 months post injection}

$\begin{array}{lcccccc}\text { Vaquerizo } 2013 & 15 & 48 & 0 & 42 & 100.0 \% & 27.20[1.68,441.24] \\ \text { Suldotal }(95 \% \mathrm{Cl}) & & 48 & & 42 & 100.0 \% & 27.20[1.68,441.24] \\ \text { Total events } & 15 & & 0 & & \end{array}$

Heterogeneity. Not applicable

Test for overall effed: $Z=2.32(P=0.02)$

Test for subaroup differences $\mathrm{Chi}^{2}=1.74 . \mathrm{df}=1(\mathrm{P}=0.19) . \mathrm{I}^{2}=42.4 \%$

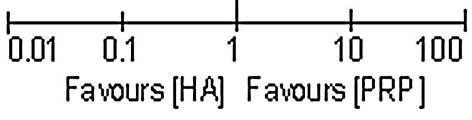

Figure 12 Forest plot of comparison: 2 platelet rich plasma (PRP) versus hyaluronic acid (HA), outcome: 2.5; function: number of patients with $50 \%$ decrease on the Western Ontario and McMaster Universities Osteoarthritis Index (WOMAC) physical function subscale.

score or assessed with the WOMAC total score) is improved significantly better after PRP injections compared with HA. Limited evidence (one study with a high risk of bias) is available that the Lequesne score is significantly higher after PRP injections compared with HA.

Kon et al reported patient satisfaction as a measure of patient global assessment. No statistically significant differences were found between PRP and HA (both high-weight and low-weight $\mathrm{HA}$ ) on the number of patients satisfied at 6 months (RR was $1.24 ; 95 \%$ CI 0.98 to 1.58 ; $\mathrm{p}$ value $=0.07$ and $1.28 ; 95 \% \mathrm{CI}$ 1.00 to $1.64 ; \mathrm{p}$ value $=0.05) .{ }^{45}$

Additionally, no statistically significant differences were detected for the number of patients reporting postinjective pain reaction (pooled RR 1.00; 95\% CI 0.65 to 1.53 ; p value 1.00$).{ }^{36} 4043$
Filardo $e \mathrm{al}^{38}$ reported a statistically significantly higher postinjective pain reaction in the PRP group ( $p$ value 0.039 ). Since no measure of dispersion was reported, this outcome was not analysed in RevMan.

\section{PRP versus PRP}

Only one non-randomised controlled trial comparing PRP with another PRP reported data on global assessment that could be used in this review. Filardo et $a l^{44}$ reported the percentage of patients satisfied with the procedure at 12 months postinjection. No statistically significant difference was detected between the single-spinning approach (76.4\% PRGF group) and the doublespinning approach (80.6\% PRP group), (RR 1.05; 95\% CI 0.89

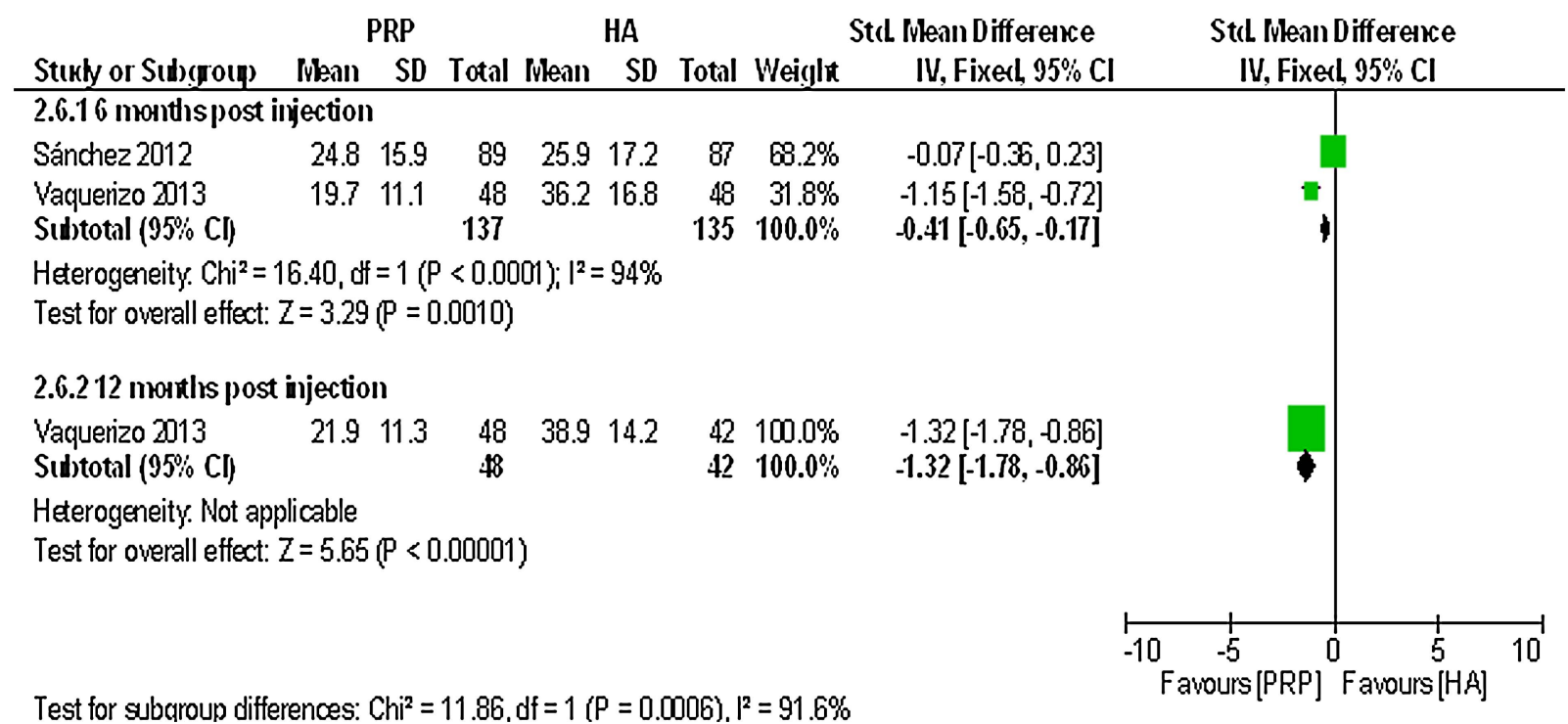

Figure 13 Forest plot of comparison: 2 platelet rich plasma (PRP) versus hyaluronic acid (HA), outcome: 2.6; function: Western Ontario and McMaster Universities Osteoarthritis Index (WOMAC) physical function subscale. 
PRP

HA

StcL Iylean Difference

StcL Mlean Difference

Stukly or Subgroup Mlean SD Total ilean SD Total Weiglt

IV, Fixech, $95 \% \mathrm{Cl}$

IV, Fixech, $95 \% \mathrm{Cl}$

2.7.11 month post injection

Cerza 2012

49.617 .7

$60 \quad 55.2 \quad 12.3$

60 $100.0 \%$

$60100.0 \%$

$-0.37[-0.73,-0.00]$

Subtotal ( $95 \%$ CI)

60

$-0.37[-0.73,-0.00]$

Heterogeneity. Not applicable

Test for overall effect: $Z=1.98(P=0.05)$

\subsubsection{3 monthspost injection}

$\begin{array}{lrrrrrrrr}\text { Cerza 2012 } & 39.1 & 17.8 & 60 & 57 & 11.7 & 60 & 7.2 \% & -1.18[-1.57,-0.79] \\ \text { LiMing 2011 } & 13.3 & 9.4 & 15 & 13.8 & 4.7 & 15 & 2.8 \% & -0.07[-0.78,0.65] \\ \text { Suldtotal }(95 \% \mathrm{Cl}) & & & \mathbf{7 5} & & & 75 & \mathbf{1 0 0 . 0 \%} & -\mathbf{0 . 9 3}[-1.27,-0.59]\end{array}$

Heterogeneity. Chi $^{2}=7.20, d f=\left.1(P=0.007)\right|^{2}=86 \%$

Test for overall effect: $Z=5.32(P<0.00001)$

2.7.36 monthspost injection

$\begin{array}{lrrrrrrrr}\text { Caza 2012 } & 36.5 & 17.9 & 60 & 65.1 & 10.6 & 60 & 22.2 \% & -1.93[-2.37,-1.50] \\ \text { Li Ming 2011 } & 10.7 & 9.9 & 15 & 20.6 & 8.3 & 15 & 7.1 \% & -1.05[-1.83,-0.28] \\ \text { Sánchez 2012 } & 74 & 42.7 & 89 & 78.3 & 48.1 & 87 & 48.3 \% & -0.09[-0.39,0.20] \\ \text { Yaquerizo 2013 } & 27.2 & 15.1 & 48 & 50.4 & 23.2 & 48 & 2.4 \% & -1.18[-1.61,-0.74] \\ \text { Sulbtotal (95\% Cl) } & & & 212 & & & 210 & 100.0 \% & -0.81[-1.02,-0.61]\end{array}$

Hederogeneity. $\mathrm{Chi}^{2}=51.09$, of $=3(\mathrm{P}<0.00001) ;\left.\right|^{2}=94 \%$

Test for overall effect: $Z=7.75(P<0.00001)$

\subsubsection{2 months post injection}

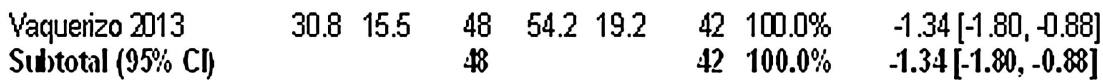

Heterogeneity. Not applicable

Test for overall effect: $Z=5.71(P<0.00001)$

Test for subaroup differences: $\mathrm{Chi}^{2}=11.37 . \mathrm{df}=3(\mathrm{P}=0.010) . \mathrm{I}^{2}=73.6 \%$

Figure 14 Forest plot of comparison: 2 platelet rich plasma (PRP) versus hyaluronic acid (HA), outcome: 2.7; function: Western Ontario and McMaster Universities Osteoarthritis Index (WOMAC) total.
HA
PRP
Risk Ratio
Risk Ratio

Study or Subgroup Events Total Events Total Weight IVI H, FixedL $95 \% \mathrm{Cl}$

[N]-H, Fixell, $95 \% \mathrm{Cl}$

2.9.1 6 months post injection

Vaquerizo 2013

Suldotal $(95 \% \mathrm{Cl})$

14

$248 \quad 100.0 \%$

$7.00[1.68,29.15]$

Total events 14

$48 \quad 100.0 \%$

$7.00[1.68,29.15]$

Heterogeneity. Not applicable

Test for overall effect: $Z=2.67(P=0.008)$

2.9.2 12 months post injection

$\begin{array}{lcccccc}\text { Vaquerizo } 2013 & 9 & 48 & 1 & 42 & 100.0 \% & 7.88[1.04,59.61] \\ \text { Sultotal }(95 \% \mathrm{Cl}) & & 48 & & 42 & 100.0 \% & 7.88[1.04,59.61] \\ \text { Total events } & 9 & & 1 & & & \end{array}$

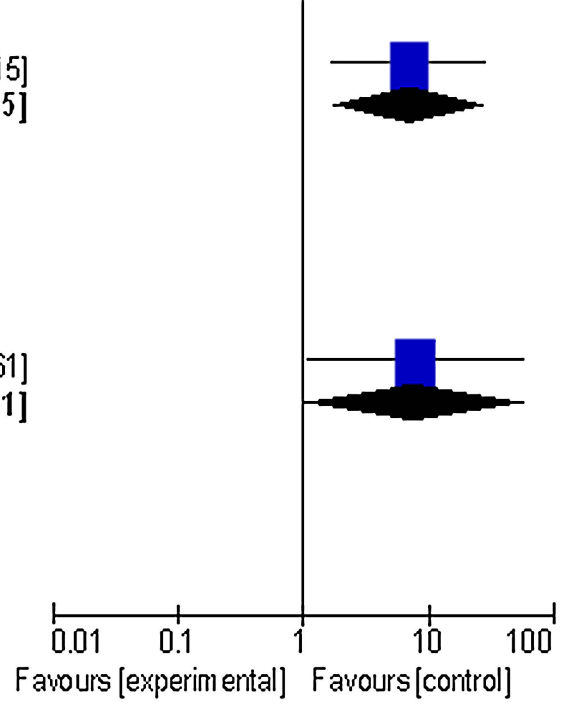

Test for subaroup differences $\mathrm{Chi}^{2}=0.01 . \mathrm{df}=1(\mathrm{P}=0.93) . \mathrm{I}^{2}=0 \%$

Figure 15 Forest plot of comparison: 2 platelet rich plasma (PRP) versus hyaluronic acid (HA), outcome: 2.9 ; function: number of patients with a $50 \%$ decrease on the Lequesne index. 


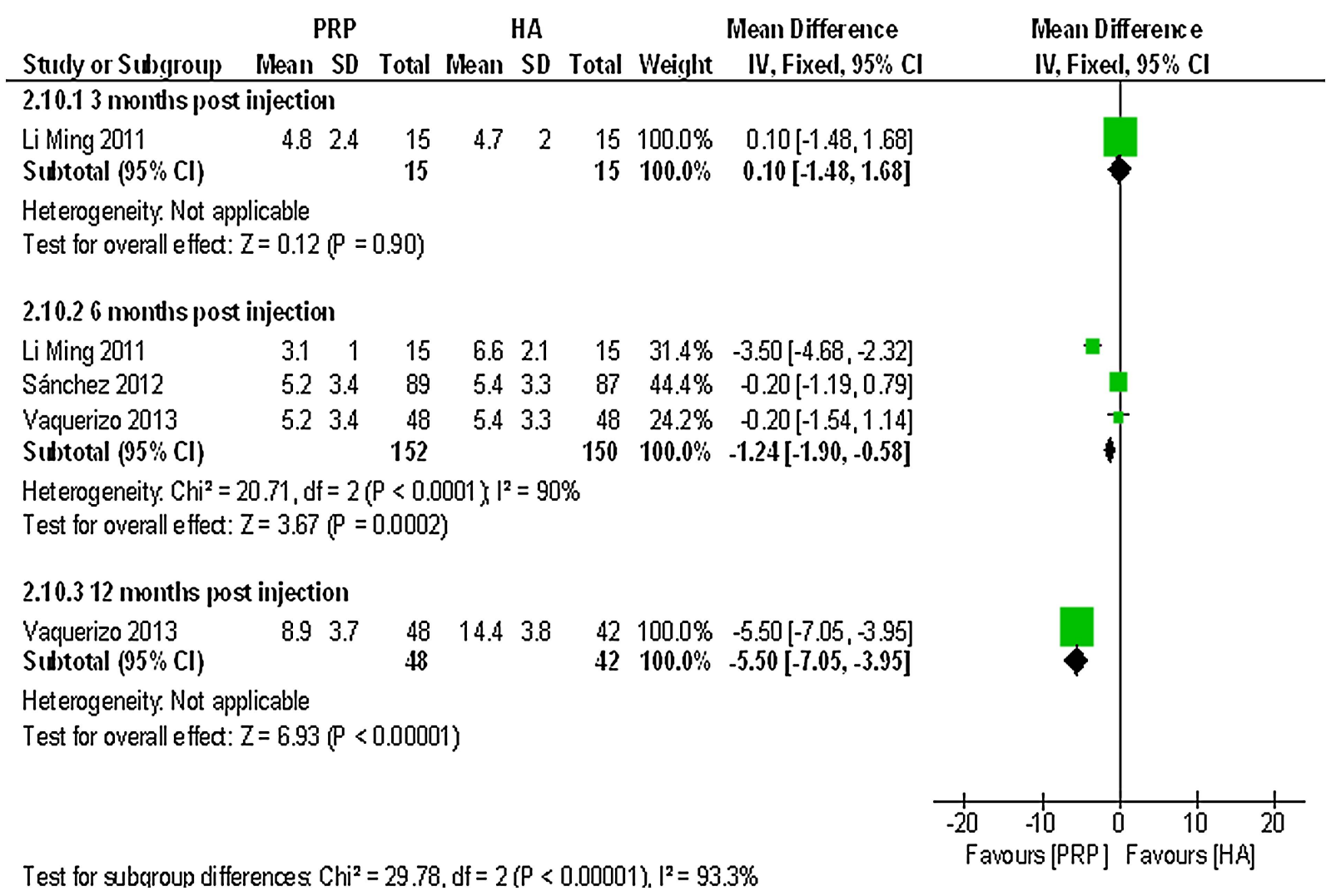

Figure 16 Forest plot of comparison: 2 platelet rich plasma (PRP) versus hyaluronic acid (HA), outcome: 2.10; function: Lequesne index (0-24 Likert).

to $1.25 ; \mathrm{p}$ value 0.54$)$. For details, please see the effect estimates (see online supplementary materials) and figure 23.

\section{DISCUSSION}

This systematic review assessed the effectiveness of PRP studied in five RCTs and five non-randomised trials. A general positive effect on pain reduction and function was found in favour of PRP injections compared with control groups. However, the level of evidence regarding the effectiveness of PRP in the treatment of OA of the knee was limited to moderate when PRP injections were compared with placebo or HA.

One RCT compared PRP with placebo and reported data from 78 patients. ${ }^{37}$ There was evidence of benefit for pain reduction and global assessment at 6 months postinjection. The analyses do not provide evidence for effects on function due to the lack of data for functional improvement. There was no statistical significant difference in the total number of patients with short time local and systemic reactions during and after the injections between a single PRP injection and placebo.

In comparisons between IA PRP injections and HA, a beneficial effect was found regarding pain reduction in favour of PRP at 6 months postinjection. ${ }^{41}{ }^{42}$ Pooled comparisons using the WOMAC pain subscale, WOMAC physical function scale or Lequesne index outcome measures were not possible because of the presence of considerable heterogeneity. When unpooled, there was no trend for functional measures (International Knee Documentation Committee (IKDC), Knee Injury and Osteoarthritis Outcome Score (KOOS) and Tegner) to have improved with PRP treatment. ${ }^{38} 414345$ A summary of intervention effects per study in time is provided in table 3 .

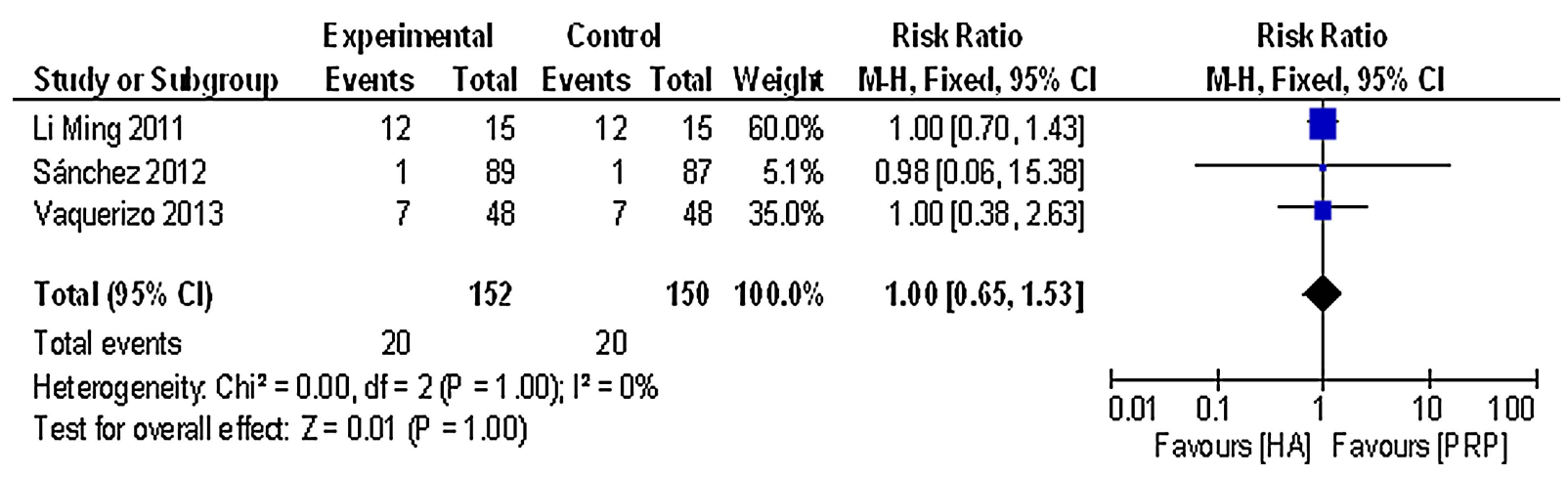

Figure 17 Forest plot of comparison: 2 platelet-rich plasma (PRP) versus hyaluronic acid (HA), outcome: 2.16; adverse effects: number of patients with local or systemic reactions related to treatment. 
PRP

HA

Stıkly or Sulkgronp Iylean SD Total Iylean SD Total Weicht

3.1.13 months post injection

Say 2013

Sultotal $(95 \% \mathrm{Cl})$$$
231.6
$$

$\begin{array}{lllll}45 & 4.1 & 1.3 & 45 & 40.9 \%\end{array}$

2.062 .02

60

105

$60 \quad 59.1 \%$

$105 \quad 100.0 \%$

Heterogeneity. $\mathrm{Chi}^{2}=1.26, \mathrm{df}=1\left(\mathrm{P}=0.26, \mathrm{l}^{2}=21 \%\right.$

Test br overal effed: $Z=6.96(P<0.00001)$

\subsubsection{6 months post injection}

$\begin{array}{lrrrrrrrr}\text { Say 2013 } & 1.7 & 1.4 & 45 & 3 & 1 & 45 & 41.5 \% & -1.06[-1.50,-0.62] \\ \text { Spaková 2012 } & 2.69 & 1.86 & 60 & 4.3 & 2.07 & 60 & 58.5 \% & -0.81[-1.19,-0.44] \\ \text { Sultototil }(95 \% \text { Cl) } & & & 105 & & & 105 & 100.0 \% & -0.92[-1.20,-0.63]\end{array}$

Heterogeneity. $\mathrm{Chi}^{2}=0.7 \mathrm{~J}, \mathrm{df}=1\left(\mathrm{P}=0.40, \mathrm{l}^{2}=0 \%\right.$

Test fr overal effed: $Z=6.29(P<0.00001)$

Test br subaroup differences $\mathrm{Chi}^{2}=0.28 \mathrm{df}=1(\mathrm{P}=0.60) . \mathrm{I}^{2}=0 \%$
Stcl. Ivlean Differ ence

IV, Ficell, 95\% $\mathrm{Cl}$

$-1.22[-1.68,-0.77]$

$-0.89[-1.26,-0.51]$
$-1.03[-1.31,-0.74]$
Stcl. Iylein Differ ence

IV, Ficell, 95\%: Cl

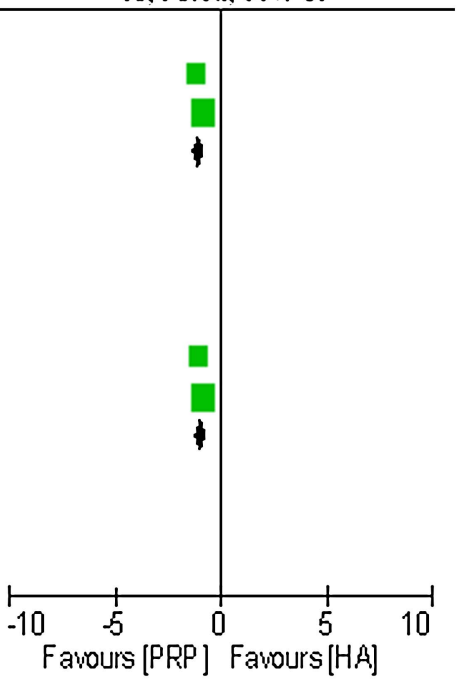

Figure 18 Forest plot of comparison: 3 platelet-rich plasma (PRP) versus hyaluronic acid (HA; non-randomised controlled trail (CCT)), outcome: 3.1; pain: visual analogue scale/numeric rating scale.

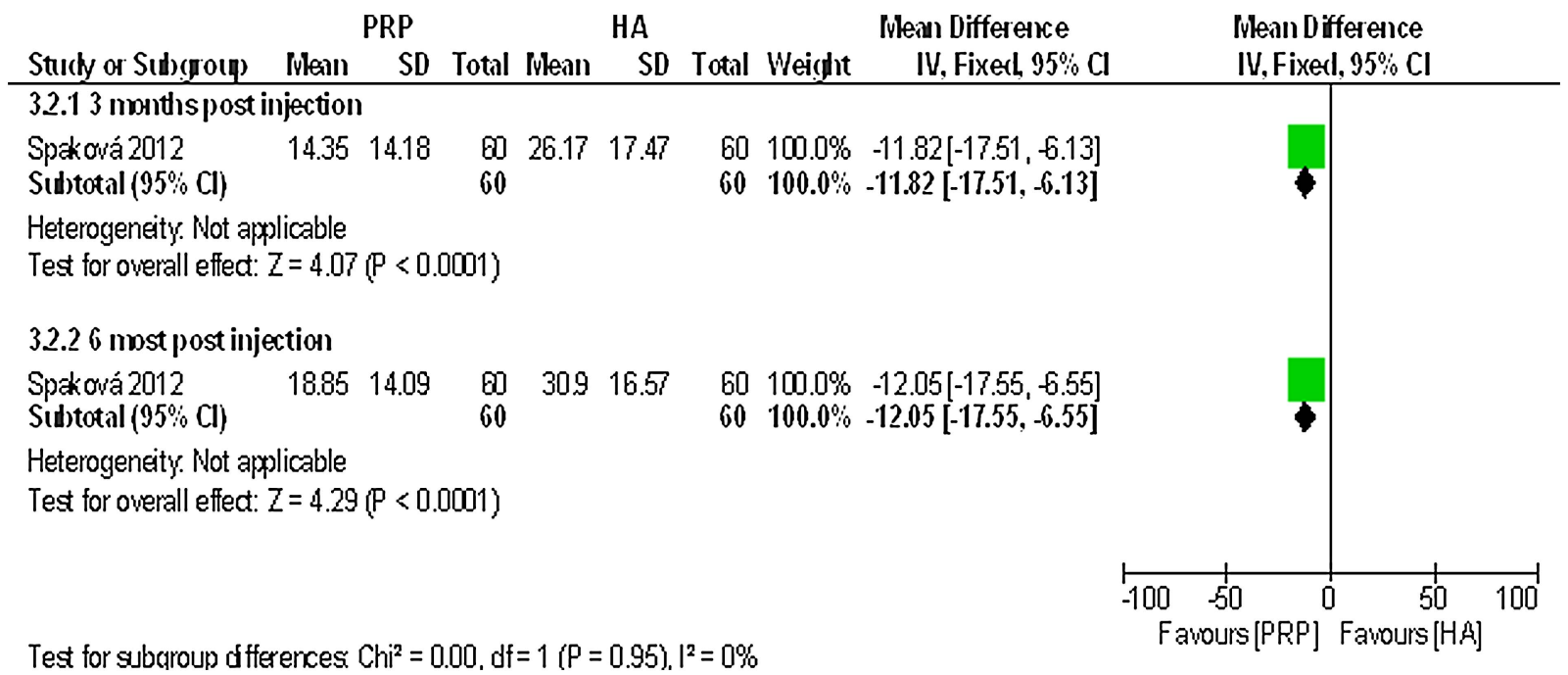

Figure 19 Forest plot of comparison: 3 platelet-rich plasma (PRP) versus hyaluronic acid (HA; non-randomised controlled trail (CCT)), outcome: 3.2; function: Western Ontario and McMaster Universities Osteoarthritis Index (WOMAC) total.
PRP
HA, HW
Risk Ratio
Risk Ratio

Study or Subgroup Events Total Events Total Weight IHH, Fixech $95 \% \mathrm{Cl}$

INI-H, Fixed, $95 \% \mathrm{Cl}$

3.6.1 6 months post injection
Kon $2011 \quad 41 \quad 50$
Sutototal $(95 \% \mathrm{Cl}) \quad 41$
Total events
Heterogeneity. Not applicable
Test for overall effed: $Z=1.79(\mathrm{P}=0.07)$

Test for subaroup differences: Not applicable

Figure 20 Forest plot of comparison: 3 platelet-rich plasma (PRP) versus hyaluronic acid (HA; non-randomised controlled trail (CCT)), outcome: 3.6; global assessment: patient satisfaction, number of patients who were satisfied (PRP vs high-weight (HW) HA). 


\begin{tabular}{|c|c|c|c|c|c|c|c|}
\hline Study or Subgroup & $\begin{array}{r}\text { PRP } \\
\text { Events }\end{array}$ & Total & $\begin{array}{r}\mathrm{HA}, \mathrm{L} \\
\text { Events }\end{array}$ & $\begin{array}{l}\text { W } \\
\text { Total }\end{array}$ & Weight & $\begin{array}{l}\text { Risk Ratio } \\
\text { IuH, Fixech, } 95 \% \mathrm{Cl}\end{array}$ & $\begin{array}{c}\text { Risk Ratio } \\
\text { IM-H, Fixell, } 95 \% \mathrm{Cl}\end{array}$ \\
\hline \multicolumn{8}{|c|}{ 3.7.1 6 months post injection } \\
\hline $\begin{array}{l}\text { Kon } 2011 \\
\text { Subtotal }(95 \% \mathrm{Cl})\end{array}$ & 41 & $\begin{array}{l}50 \\
50\end{array}$ & 32 & $\begin{array}{l}50 \\
50\end{array}$ & $\begin{array}{l}100.0 \% \\
100.0 \%\end{array}$ & $\begin{array}{l}1.28[1.00,1.64] \\
1.28[1.00,1.64]\end{array}$ & 5 \\
\hline $\begin{array}{l}\text { Total events } \\
\text { Heterogeneity. Not ak } \\
\text { Test for overall effec: }\end{array}$ & $\begin{array}{l}41 \\
\text { licable } \\
=1.98\end{array}$ & $=0.05$ & 32 & & & & \\
\hline & & & & & & & \begin{tabular}{|ccccc}
0.01 & 0.1 & 1 & 10 & 100 \\
Favours [PRP] & Favours [ $[\mathrm{HA}$, LM]
\end{tabular} \\
\hline
\end{tabular}

Figure 21 Forest plot of comparison: 3 platelet-rich plasma (PRP) versus hyaluronic acid (HA; non-randomised controlled trail (CCT)), outcome: 3.7; global assessment: patient satisfaction, number of patients who were satisfied (PRP vs low weight (LW) HA).

The variance of patient reported outcome measures $\left(\mathrm{PROMs}^{48}\right)$ used in the included studies made it difficult to compare the results. As recommended by the OMERACT III conference, four domains should be evaluated in OA clinical trials: pain, physical function, patient global assessment, and, for studies of 1 year or longer, joint imaging. ${ }^{29}$ Although the WOMAC is the instrument currently used, other valid and reliable instruments can be used to measure the domains as indicated in patients with OA. ${ }^{49}{ }^{50}$ In addition to this, no superiority of any outcome measure to another has been studied in patients with OA as yet. ${ }^{49}$ All included studies reported a minimal one of the first three OMERACT domains. None of them evaluated changes on joint imaging. Follow-up moments of 6 months were too short to investigate whether PRP injections are associated with changes in MRI. Halpern et $a l^{20}$ detected, in a prospective non-comparative study with 22 patients, no change per compartment in at least $73 \%$ of cases at 12 months follow-up.

The level of degeneration of the knee in all studies was one of the inclusion criteria. On the basis of this level of degeneration, a few studies reported more promising results for the use of PRP in knees with a lower level of joint degeneration. ${ }^{38} 4045$ The K\&L classification criteria and the Ahlbäck classification criteria are two different classification systems used in the included studies to classify the level of joint degeneration. ${ }^{51}$ Not only the differences in descriptions between classification systems but also differences in descriptions of grades of knee OA within a classification system are reported by Schiphof et al. ${ }^{52}$ The included studies in this review mentioned only classification grades of knee OA or referred to original studies without a narrow description. In addition to these two studies, the level of degeneration was categorised in three groups: cartilage degeneration, early OA and advanced OA. ${ }^{44}$ Regarding this variance of level of degeneration between and probably within the included studies, no conclusions can be drawn about the possible effect of PRP injections on a specific classification of OA.

Platelets contain growth factors, cytokines, chemokines, as well as dense and lisosomal granules. ${ }^{53-55}$ The release of these may play a special role in cartilage repair including modulating inflammatory processes, cell proliferation, chemotaxis, migration, differentiation and syntheses of matrix. ${ }^{16} 1756$ Although the results of these laboratory studies are encouraging and set the rationale for the treatment of platelet concentrates, there is still uncertainty about the optimal formulation of PRP. Most of the included studies in this review employed a different type of PRP based on the preparation method (single or double spinning) and cellular content (concentration of platelets, whether or not activated prior to injection and the presence of leucocytes). The influence of various variables in the comparison of different types of PRP will lead to different biological and physiological processes and with this probably different effectiveness. ${ }^{14}$ In addition, the different therapeutic protocols used in the studies introduce further confounding factors.

Safety is an important aspect considering PRP as conservative treatment. This review was detected in the placebo-controlled study as well as in the comparison with HA studies with no statistically significant differences in the total number of patients with short time local and systemic reactions during and after the injections. ${ }^{36-40}$ Controversially, Patel et al's study reported more short time local and systematic reactions in the two PRP injections group. ${ }^{36}$ It is obvious that more injections are probably

\begin{tabular}{|c|c|c|c|c|c|c|c|}
\hline Studly or Suldgroup & $\begin{array}{r}\text { PRP } \\
\text { Events }\end{array}$ & Total & $\begin{array}{r}\text { HA } \\
\text { Events }\end{array}$ & Total & Weight & $\begin{array}{l}\text { Risk Ratio } \\
\text { IUL-H, Fixedl, } 95 \% \mathrm{Cl}\end{array}$ & $\begin{array}{c}\text { Risk Ratio } \\
\text { IVI-H, FixedL } 95 \% \mathrm{Cl}\end{array}$ \\
\hline Spaková 2012 & 6 & 30 & 0 & 30 & $100.0 \%$ & $13.00[0.76,220.96]$ & \\
\hline Total $(95 \% \mathrm{Cl})$ & & 30 & & 30 & $100.0 \%$ & $13.00[0.76,220.96]$ & \\
\hline Total events & 6 & & 0 & & & & \\
\hline $\begin{array}{l}\text { Heterogeneity. Not ap } \\
\text { Test for overall e ffect }\end{array}$ & $\begin{array}{l}\text { licable } \\
=1.77 \text { (F }\end{array}$ & $=0.08$ & & & & & $\begin{array}{cccc} & 1 & 1 & 1 \\
0.01 & 0.1 & 1 & 10 \\
& \text { Favours [PRP] } & \text { Favours [H }\end{array}$ \\
\hline
\end{tabular}

Figure 22 Forest plot of comparison: 3 platelet-rich plasma (PRP) versus hyaluronic acid (HA; non-randomised controlled trail (CCT)), outcome: 3.10; adverse effects: number of patients with local or systemic reactions related to treatment. 


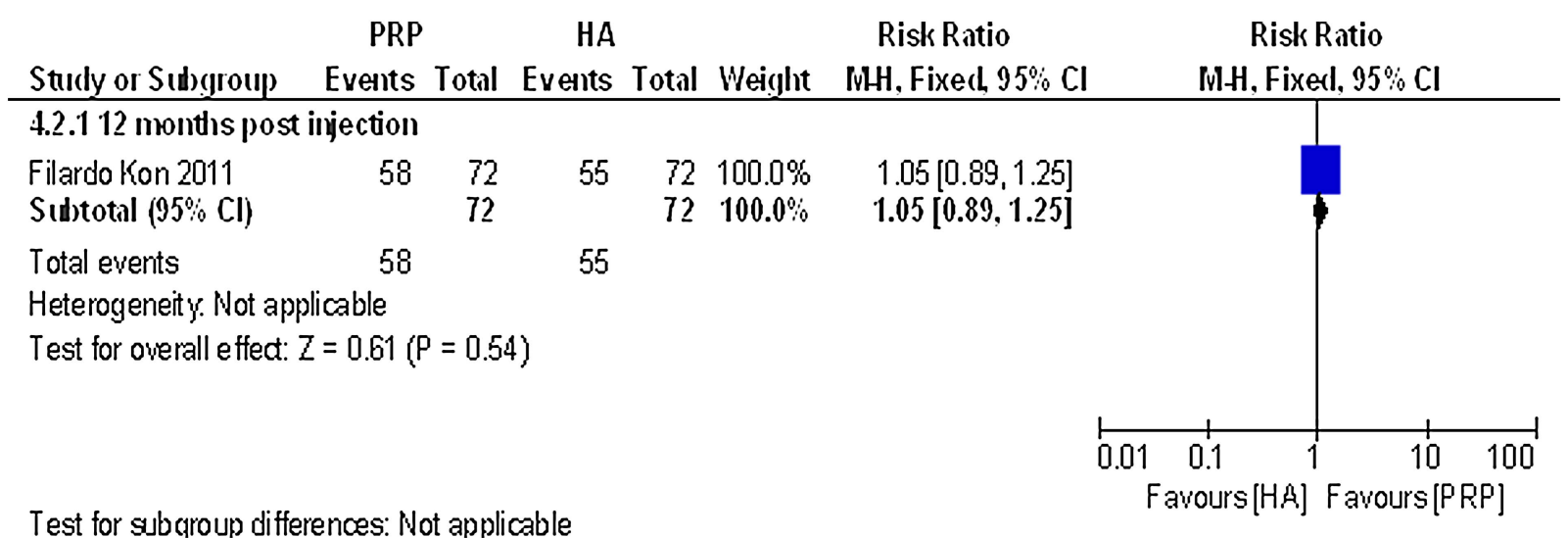

Figure 23 Forest plot of comparison: 4 PRP—single spinning—versus PRP—double spinning—(CCT), outcome: 4.2; global assessment: patient satisfaction, number of patients who were satisfied (CCT, non-randomised controlled trail; HA, hyaluronic acid; PRP, platelet-rich plasma).

responsible for the higher amount of adverse reactions, but regarding this one study, no conclusions can be made about the dose response relationship.

Another important aspect to consider when interpreting the results is the study quality. Except for the study by Sánchez et $a l^{40}$ all RCTs and all non-randomised controlled trials revealed a high risk of bias.

All RCTs, except Sánchez et al's trial, presented performance bias due to the impossibility to blind personnel and participants. Patel et al aimed to blind the participants; however, the differently used dosage in one PRP group made it difficult to blind the participants and it remains unclear if performance bias is present.

Two RCTs were deficient in the reporting of randomisation procedures. ${ }^{37} 39$ Cerza et al only reported that participants were randomised, but they gave no explanation regarding the procedure. Both studies did not report the method used to conceal the allocation sequence in sufficient detail. This makes it difficult to assess the study quality. In general, the effects found in the studies comparing PRP with placebo and PRP with HA were probably influenced by several biases.

Both the three non-randomised controlled trials that assessed the effect of PRP injections comparing HA and the nonrandomised trial comparing two different types of PRP had many systemic errors including selection, performance, attrition and detection bias. ${ }^{41} 424445$ In all studies without randomisation, both participants and personnel were unblinded to the treatments. Also, blinding the outcome assessor was not reported and this can lead to detection bias. Additional selection bias may have been present in the studies by Filardo $e t a l^{44}$ and Kon et $a l^{45}$ The patient treatment allocation was determined by the hospital at which the patients were seen. No further information was present regarding the treatment to which the groups were assigned. There are reliable criteria to identify and grade OA used in this studies. No statistically significant differences were found among the groups regarding the grade of OA. Therefore, we conclude that this inequality may not have been present. All the biases described may have led to the treatment effects found in the studies comparing PRP with HA and other types of PRP.

\section{Limitations of this systematic review}

This review was limited by the small number of studies included $(n=10)$ and the fact that only one RCT compared PRP with placebo. A second limitation is that our review used the
Cochrane Collaboration's tool for assessing risk of bias for both RCTs and non-randomised trials. Owing to the lack of a widely acceptable tool to assess non-randomised trials, we decided to use a domain based evaluation instead of a scale or checklist. ${ }^{30}$

Another limitation is that an included study published in the Chinese language was not translated. ${ }^{43}$ The results of this trial could be extracted because they were reported in the English language. However, quality assessment could not be made and that made it impossible to draw conclusions about the results that were found because of the probable undetectable systematic error.

\section{Recommendations for research}

All included studies described an equal explanation of the biological basis for the chosen intervention. Although there is consensus about the potential beneficial effect of PRP, the exact mechanisms of how a high platelet concentration coordinates an inflammatory, proliferative or remodelling response are still unknown. A better understanding of how platelets affect these healing mechanisms in degenerative cartilage tissues is important to develop more precise formulations and applications of PRP. More specifically, questions regarding the optimal platelet concentration, activation procedure, inclusion or exclusion of leucocytes and the optimal preparation, dosage and number of applications need to be addressed. Therefore, more detailed in vitro studies will be necessary before proper interventions can be assessed in future research.

These intervention studies should use equal validated disease specific and PROMs. A potential guideline in outcome measures in studies with patients with OA could be the criteria as recommended by the task force of the OARSI. ${ }^{49}$

Finally, there is a need for large high-quality RCTs to avoid potential bias in selection, performance and attrition.

\section{Conclusion}

On the basis of the current evidence, PRP injections reduced pain more effectively than did placebo injections in OA of the knee (level of evidence: limited due to the high risk of bias). This significant effect on pain was also seen when PRP injections were compared with HA injections (level of evidence: moderate due to the generally high risk of bias). Additionally, function improved significantly more when PRP injections were compared with controls (limited to moderate evidence). More large randomised studies of good quality and low risk of bias are needed to test whether PRP injections should be a routine part of management of patients with OA of the knee. 


\section{What this study adds}

- A thorough systematic review about the effects of platelet-rich plasma on knee osteoarthritis (OA).

- An insight into the high risk of bias in the available studies on this topic.

- A possible addition to conservative treatment options for knee OA.

Contributors ABML conducted the study, analysed the data and wrote the manuscript. EWPB planned the study and was available for parts of the data analysis and corrected the manuscript. MR analysed the data and corrected the manuscript. MHM planned the study, analysed the data, and corrected and submitted the manuscript.

Competing interests None.

Provenance and peer review Not commissioned; externally peer reviewed.

\section{REFERENCES}

1 Lane NE, Brandt $\mathrm{K}$, Hawker G, et al. OARSI-FDA initiative: defining the disease state of osteoarthritis. Osteoarthritis Cartilage 2011;19:478-2.

2 Suri P, Morgenroth DC, Hunter DJ. Epidemiology of osteoarthritis and associated comorbidities. PM\&R 2012;4:S10-19.

3 Arden N, Nevitt MC. Osteoarthritis: epidemiology. Best Prac Res Clin Rheumatol 2006;20:3-25

4 Felson DT, Lawrence RC, Dieppe PA, et al. Osteoarthritis: new insights. Part 1: the disease and its risk factors. Ann Intern Med 2000;133:635-46.

5 Lawrence RC, Felson DT, Helmick CG, et al. Estimates of the prevalence of arthritis and other rheumatic conditions in the United States. Part II. Arthritis Rheum 2008:58:26-35.

6 Carr AJ, Robertsson 0, Graves $S$, et al. Knee replacement. Lancet 2012;379:1331-40.

7 ACR 2000 American College of Rheumatology Subcommittee on osteoarthritis guidelines. Recommendations for the medical management of osteoarthritis of the hip and knee. 2000 Update. Arthritis Rheum 2000;43:1905-15.

8 Felson DT, Zhang Y, Anthony JM, et al. Weight loss reduces the risk for symptomatic knee osteoarthritis in woman. The Framingham Study. Ann Intern Med 1992;116:535-9.

9 Zang W, Moskowitz RW, Nuki G, et al. OARSI recommendations for the management of hip and knee osteoarthritis. Part II: OARSI evidence-based, expert consensus guidelines. Osteoarthritis Cartilage 2008;16:137-62.

10 Bellamy N, Campbell J, Robinson V, et al. Intraarticular corticosteroid for treatment of osteoarthritis of the knee. Cochrane Database Sys Rev 2006;19:CD005328.

11 Hepper CT, Halvorson JJ, Duncan ST, et al. The efficacy and duration of intra-articular corticosteroid injection for knee osteoarthritis: a systematic review of level I studies. J Am Acad Orthop Surg 2009;17:638-46.

12 Fortier LA, Barker JU, Strauss EJ, et al. The role of growth factors in cartilage repair. Clin Orthop Relat Res 2011:469:2706-15.

13 Smelter E, Hochberg MC. New treatments for osteoarthritis. Curr Opin Rheumatol 2013:25:310-16.

14 Mishra A, Harmom K, Woodall J, et al. Sports medicine applications of platelet rich plasma. Curr Pharm Biotechnol 2012;13:1185-95.

15 Andia I, Sánchez M, Maffulli N. Joint pathology and platelet-rich plasma therapies. Expert Opin Biol. Ther 2012;12:7-22.

16 Kon E, Filardo G, Di Martino A, et al. Platelet-rich plasma (PRP) to treat sports injuries: evidence to support its use. Knee Surg Sports Traumatol Arthrosc 2011:19:516-27.

17 Cole BJ, Seroyer ST, Filardo G, et al. Platelet-rich plasma: where are we now and where are we going. Sports Health 2010;2:203-10.

18 Woodell-May JE, Pietrzak WS. Platelet-rich plasma in orthopaedics. In: Pietrzak WS, ed. Orthopedic biology and medicine: muskuloskeletal tissue regeneration. Totawa, NJ: Humana Press, 2008:547-68.

19 Jang S-J, Kim J-D, Cha S-S. Platelet-rich plasma (PRP) injections as an effective treatment for early osteoarthritis. Eur J Orthop Surg Traumatol 2013:23:573-80.

20 Halpern B, Chaudhury S, Rodeo SA, et al. Clinical and MRI outcomes after platelet-rich plasma treatment for knee osteoarthritis. Clin I Sport Med 2013;23:238-39.

21 Gobbi A, Karnatzikos G, Mahajan V, et al. Platelet-rich plasma treatment in symptomatic patients with knee osteoarthritis: preliminary results in a group of active patients. Sports Health 2012;4:162-72.
22 Sampson S, Reed M, Silvers $\mathrm{H}$, et al. Injection of platelet-rich plasma in patients with primary and secondary knee osteoarthritis: a pilot study. Am J Phys Med Rehabil 2010;89:961-9

23 Filardo G, Kon E, Buda R, et al. Platelet-rich plasma intra-articular knee injections for the treatment of degenerative cartilage lesions and osteoarthritis. Knee Surg Sports Traumatol Arthosc 2011;19:528-35.

24 Wang-Saegusa $A$, Cugat $R$, Ares 0 , et al. Infiltration of plasma rich in growth factors for osteoarthritis of the knee short-term effects on function and quality of life. Arch Orthop Trauma Surg 2011;131:311-17.

25 Kon E, Buda R, Filardo G, et al. Platelet-rich plasma: intra-articular knee injections produced favorable results on degenerative cartilage lesions. Knee Surg Sports Traumatol Arthrosc 2010:18:472-9.

26 Napolitano M, Matera S, Bossio M, et al. Autologous platelet gel for tissue regeneration in degenerative disorders of the knee. Blood Transfus 2012;10:72-7.

27 Buhr M, Siekmann W. Intra-articular injection of platelet rich plasma for cartilage repair [Intraartikuläre Injection von thrombozytenangereichertem Plasma zur Behandlung von Knorpelschäden]. Orthopädische Praxis 2009:45:10-16.

28 Altman R, Asch E, Bloch D, et al. Development of criteria for the classification and reporting of osteoarthritis. Classification of osteoarthritis of the knee. Arthritis Rheum 1986;29:1039-49.

29 Bellamy N, Kirwan J, Boers M, et al. Recommendations for a core set of outcome measures for future phase III clinical trials in knee, hip and hand osteoarthritis. Consensus development at OMERACT III. J Rheumatol 1997;24:799-802.

30 Higgins JPT, Green S, eds. Cochrane handbook for systematic reviews of interventions, version 5.1.0 [updated March 2011]. The Cochrane Collaboration, 2011.

31 Slavin RE. Best evidence synthesis: an intelligent alternative to meta-analysis. J Clin Epidemiol 1995;48:9-18.

32 Van Tulder M, Furlan A, Bombardier C, et al:; Editorial Board of the Cochrane Collaboration Back Review Group. Updated method guidelines for systematic reviews in the Cochrane Collaboration Back Review Group. Spine 2003;28:1290-9.

33 Yang KGA, Raijmakers NJH, van Arkel ERA, et al. Autologous interleukin-1 receptor antagonist improves function and symptoms in osteoarthritis when compared to placebo in a prospective randomized controlled trial. Osteoarthritis Cartilage 2008;16:498-505.

34 Baltzer AW, Moser C, Jansen SA, et al. Autologous conditioned serum (Orthokine) is an effective treatment for knee osteoarthritis. Osteoarthritis Cartilage 2009;17:152-60

35 Klatt BA, Lopez HL, Segal NA, et al. Treatment options in knee osteoarthritis: total knee arthroplasty versus platelet-rich plasma. PM R 2011;3:377-86.

36 Vaquerizo V, Placencia MA, Arribas I, et al. Comparison of intra-articular injections of plasma rich in growth factors versus Durolane hyaluronic acid in the treatment of patients with symptomatic osteoarthritis: a randomized controlled trail. Arthroscopy 2013:29:1635-43.

37 Patel S, Dhillon MS, Aggerwal S, et al. Treatment with platelet-rich plasma is more effective than placebo for knee osteoarthritis: a prospective, double-blind, randomized trail. Am I Sports Med 2013:41:356-4.

38 Filardo G, Kon E, Di Martino A, et al. Platelet-rich plasma versus hyaluronic acid to treat knee degenerative pathology: study design and preliminary results of a randomized controlled trail. BMC Musculoskelet Disord 2012;13:229.

39 Cerza F, Carni S, Carcangiu A, et al. Comparison between hyaluronic acid and platelet-rich plasma, intra-articular infiltration in the treatment of gonarthrosis. Am J Sports Med 2012:40:2822-7.

40 Sánchez M, Fiz N, Azofra J, et al. A randomized clinical trial evaluating plasma rich in growth factors (PRGF-Endoret) versus hyaluronic acid in the short-term treatment of symptomatic knee osteoarthritis. Arthroscopy 2012;28:1070-8.

41 Say F, Gürler D, Yener $K$, et al. Platelet-rich plasma injection is more effective than hyaluronic acid in the treatment of knee osteoarthritis. Acta Chir Orthop Traumatol Cech 2013;80:278-3.

42 Spaková T, Rosocha J, Lacko M, et al. Treatment of knee joint osteoarthritis with autologous platelet-rich plasma in comparison with hyaluronic acid. Am J Phys Med Rehabil 2012:91:411-17.

43 Li M, Zhang C, Ai Z, et al. Therapeutic effectiveness of intra-knee-articular injection of platelet rich plasma on knee articular cartilage degeneration. Zhongguo Xiu Fu Chong Jian Wai Ke Za Zhi 2011;25:1192-6.

44 Filardo G, Kon E, Ruiz MTP, et al. Platelet-rich plasma intra-articular injections for cartilage degeneration and osteoarthritis: single- versus double-spinning approach. Knee Surg Sports Traumatol Arthrosc 2012;20:2082-91.

45 Kon E, Mandelbaum B, Buda $R$, et al. Platelet-rich plasma intra-articular injection versus hyaluronic acid viscosupplementation as treatments for cartilage pathology: from early degeneration to osteoarthritis. Arthroscopy 2011;27:1490-501.

46 Mishra A, Harmon K, Woodall J, et al. Sports medicine applications of platelet rich plasma. Curr Pharm Biotech 2012;13:1185-95.

47 Collins N, Misra D, Felson D, et al. Measures of knee function: International Knee Documentation Committee (IKDC) Subjective Knee Evaluation Form, Knee Injury and Osteoarthritis Outcome Score (KOOS), Knee Injury and Osteoarthritis Outcome Score Physical Function Short Form (KOOS-PS), Knee Outcome Survey Activities of Daily Living Scale (KOS-ADL), Lysholm Knee Scoring Scale, Oxford Knee Score (OKS), Western Ontario and McMaster Universities Osteoarthritis Index (WOMAC), Activity 
Rating Scale (ARS), and Tegner Activity Score (TAS). Arthritis Care Res (Hoboken) 2011;63(Suppl 11):S208-28.

48 Davidson M, Keating J. Patient-reported outcome measures (PROMs): how should I interpret reports of measurement properties? A practical guide for clinicians and researchers who are not biostatisticians. Br J Sports Med 2014;48:792-6.

49 Pham T, Heijde D, Lassere M, et al. Outcome variables for osteoarthritis clinical trials: The OMERACT-OARSI set of responder criteria. J Rheumatol 2003:30:1648-54.

50 Williams V, Piva S, Irrgang J, et al. Comparison of reliability and responsiveness of patient-reported clinical outcome measures in knee osteoarthritis rehabilitation. J Orthop Sports Phys Ther 2012;42:716-23.

51 Petersson IF, Boegård T, Saxne T, et al. Radiographic osteoarthritis of the knee classified by the Ahlbäck and Kellgren \& Lawrence systems for the tibiofemoral joint in people aged 35-54 years with chronic knee pain. Ann Rheum Dis 1997;56:493-6.

52 Schiphof D, Boers M, Biersma-Zeinstra S. Differences in descriptions of Kellgren and Lawrence grades of knee osteoarthritis. Ann Rheum Dis 2008;67:1034-6.

53 Boswell S, Cole B, Sundman E, et al. Platelet rich plasma: a milieu of bioactive factors. Arthroscopy 2012;28:429-39.

54 Foster T, Puskas B, Mandelbaum B, et al. Platelet-rich plasma: from basic science to clinical applications. Am J Sports Med 2009;37:2259-72.

55 Anitua E, Andia I, Ardanza B, et al. Autologous platelets as a source of proteins for healing and tissue regeneration. Tromb Haemost 2004;91:4-15.

56 Eppley B, Woodell J, Higgens J. Platelet quantification and growth factor analysis from platelet rich plasma: implications for wound healing. Plast Reconstr Surg 2004;114:1502-8. 